\title{
SIMILARITY OR DIFFERENCE AS A BASIS FOR JUSTICE: MUST ANIMALS BE \\ LIKE HUMANS TO BE LEGALLY PROTECTED FROM HUMANS?
}

\author{
TAIMIE L. BRYANT*
}

INTRODUCTION

On November 6, 1960, Jane Goodall observed two chimpanzees stripping the leaves off of twigs, inserting them into termite mounds, and eating the termites they extracted. ${ }^{1}$ In reply to Goodall's telegram carrying this news, Louis Leakey responded: "Now we must redefine tool, redefine Man, or accept chimpanzees as humans." By stating that one of our choices is "accepting chimpanzees as humans," rather than simply "redefining chimpanzees" (without reference to humans), Leakey suggests that dramatic consequences could flow from finding similarities between chimpanzees and humans. If chimpanzees are accepted as humans and if justice requires that like entities be treated alike, justice would require legal protection of chimpanzees from exploitation to which chimpanzees-but not humans-are subject. This has been the argument and goal of The Great Ape Project. ${ }^{3}$ Indeed, it is the argument and goal of much of animal advocacy.

If humans are defined in some significant measure by a particular characteristic (such as toolmaking ability, self-awareness, or the capacity to suffer), questions of justice arise when animals are sufficiently similar to humans as to that characteristic and justice is defined as requiring that like entities be treated alike. In the context of that definition of justice, finding that

Copyright $\left(C^{2} 2007\right.$ by Taimie L. Bryant

This article is also available at http://www.law.duke.edu/journals/lcp.

* Professor of Law, UCLA School of Law.

The author thanks Scott Dewey, Bill Reppy, and Vicki Steiner for their thoughtful comments on various drafts of the manuscript. Lynn McClelland, Daniel McKenzie, and Matthew Moore provided prompt and thoughtful research assistance, which was funded by Bob Barker's generous endowment of UCLA Law School for animal law scholarship and teaching. Special thanks to Christine Littleton for her comments on those parts of this article that concern equality theory as applied to animal protection law.

1. Jane Goodall, The Chimpanzees of the Gombe: Patterns of Behavior 535 (1986). Goodall describes other types of toolmaking and tool usage. Id. at 535-42.

2. Jane Goodall, Learning from the Chimpanzees: A Message Humans Can Understand, 282 SCI. 2184, 2184-85 (1998), available at http://www.sciencemag.org/cgi/content/full/282/5397/2184.

3. See generally THE GREAT APE PROJECT: EQUALITY BEYOND HUMANITY (Paola Cavalieri \& Peter Singer eds., 1993) [hereinafter THE GREAT APE PROJECT]. 
animals are similar to humans as to one or more essential characteristics has greater significance than mere satisfaction of intellectual curiosity about animals. It calls into question the morality of such human practices as sport hunting and fishing, flesh-food production methods, and the consumption of flesh foods. The argument is, if justice requires that like entities be treated alike, it cannot be just to hunt or consume animals (who are like humans), because humans (who are like animals) are not subject to being hunted or turned into food products. Justice may not require that animals be exactly the same as humans (for instance, the number of toes and the presence of fur may not be relevant) or that they have rights exactly coterminous with the rights of humans, but justice would require that animals receive protection in ways that match up with those similarities they share with humans that are characteristics considered essential to our understanding of what it means to be human. Stated generally, the argument is that if animals are similar to humans as to capacities and characteristics of humans that define humans, then animals should receive protections equivalent to the protections of humans because a just society treats like entities alike. I refer to this as "the similarity argument."

The similarity argument - that justice requires the like treatment of like entities-drove the civil rights movement, the feminist movement, and the disability rights movement. ${ }^{4}$ Not surprisingly, then, the similarity argument also dominates advocacy for animals. ${ }^{5}$ This is so regardless of whether the goal is animal rights or the more humane use of animals. Although advocates may rest their claim on animals' cognitive capacity, on animals' capacity to suffer, or on some combination of the two, ${ }^{6}$ the argument is the same: justice requires that

4. See, e.g., Kenneth L. Karst, Belonging to America: Equal Citizenship And the CONSTITUTION (1989) (documenting the desire to belong as motivating "outsiders" and their utilization of constitutional law to secure equal, albeit often only formally equal, treatment in American society); William M. NeWman, American Pluralism: A Study of MinORITy Groups AND SOCIAL THEORY 59 (1973) (describing assimilation by immigrant groups, when " $[\mathrm{t}]$ he central tenet ... was that new groups must conform to the cultural tradition of the majority or dominant group"); William N. Eskridge, Jr., Channeling: Identity-Based Social Movements and Public Law, 150 U. PA. L. REV. 419, 465, 475 (2001); William N. Eskridge, Jr., Some Effects of Identity-Based Social Movements on Constitutional Law in the Twentieth Century, 100 MiCH. L. REV. 2062, 2071, 2072 (2002); Nancy Levit, A Different Kind of Sameness: Beyond Formal Equality and Antisubordination Strategies in Gay Legal Theory, 61 OHIO ST. L.J. 867, 919-21 (2000) (discussing shared-humanity theory as a means of addressing the dangers of theories of sameness and "homogenizing" strategies associated with the similarity argument); Christine A. Littleton, Reconstructing Sexual Equality, 75 CAL. L. REV. 1279, 1287-91 (1987).

5. Philosopher Christoph Anstötz discusses the history of the idea of equality as "a story of the development of the moral requirement to give up unjustified forms of discrimination." He traces it through various movements and into the context of the animal protection movement. Christoph Anstötz, Profoundly Intellectually Disabled Humans and the Great Apes: A Comparision, in THE GREAT APE PROJECT, supra note 3, at 158-60.

6. Scholars focused on justifications for entitlements in animals to better treatment by humans have traditionally focused on cognition, or sentience, or both. See TOM REGAN, THE CASE FOR ANIMAL RIGHTS (3d ed. 2004) (arguing in support of rights for animals with sufficient consciousness to have desires, plans, and a sense of the future: in other words, animals who are "subjects-of-a-life");

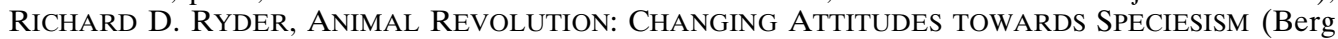
2000) (1989) (emphasizing sentience as the primary factor that justifies animal rights); PETER SINGER, ANIMAL LIBERATION (1975) (arguing for the consideration of animal interests in avoiding suffering); 
animals be protected from human (ab)use because animals are similar enough to humans to be given protections similar to those that humans have from each other.?

The animal rights perspective calls for freedom from any and all exploitation by humans, and, as most rigorously developed in the legal context by law scholar Gary L. Francione, that perspective identifies animals' legal status as private property as the legal basis for humans' exploitation of animals. ${ }^{8}$ Unlike advocates for more humane treatment of animals who do not challenge the legal property status of animals, rights advocates challenge the legal status of animals as property in order to eliminate human use of animals, whether or not such use is considered to be humane.' Despite that ideological difference, both humane-treatment claims and rights claims currently rest largely on the similarity argument. Since, for the purposes of this article, there is little need to distinguish between proponents of humane treatment and proponents of animal

SteVen Wise, RAtTling the CAge: Toward Legal Rights for Animals (2000) (adopting the view that as science confirms the cognitive capacities and consciousness of animals, animals should be accorded rights to be free from exploitation); Gary Francione, Our Hypocrisy, NEW SCIENTIST, June 4, 2005, at 51-52 (stating that the most important characteristic of a nonhuman animal for purposes of rights entitlement is sentience and rejecting a "like-mind" basis of entitlement); see also Anstötz, supra note 5, at 168-70,158-72; Brigid Brophy, The Rights of Animals, in POLITICAL THEORY AND ANIMAL RighTs 156, 159 (Paul A.B. Clarke \& Andrew Linzey eds., 1990); Heta Häyry \& Matti Häyry, Who's Like Us, in THE GREAT APE PROJECT, supra note 3, at 173-76, 173-82; James Rachels, Why Darwinists Should Support Equal Treatment for Other Apes, in THE GREAT APE PROJECT, supra note 3 , at 155, 152-57; SINGER, supra, at 163, 162-67.

7. In his overview of the field of animal rights, Clifford J. Sherry writes of Tom Regan and Peter Singer, as leaders in the field, that both are drawn to analytical ethics, in which a central tenet is universality, "which means that any ethical prescription is applicable to everyone in relatively similar circumstances. If a duty can be extended to more people or situations, then analytical ethics demands that it must be extended. Further, if different moral judgments are made in two different cases, analytical ethics demands that one must demonstrate a morally relevant difference between the cases." Clifford J. SHerry, ANimAl Rights: A ReFerence HANDBOOK 4 (1994); see also Stephen M. Wise, Animal Rights One Step at a Time, in ANIMAL Rights: CURRENT DEBATES AND NEW DiRECTIONS 19 (Cass R. Sunstein \& Martha C. Nussbaum eds., 2004) [hereinafter ANIMAL RigHTs] ("Equality demands that likes be treated alike. Equality rights therefore depend upon how one rightless animal compares to another with rights." Id. at 30); REGAN, supra note 6, at 248 ("If individuals have equal inherent value, then any principle that declares what treatment is due them as a matter of justice must take their equal value into account."). These positions are taken largely in opposition to the perspective that species membership determines just treatment. Richard Ryder, who coined the term "speciesism," wrote in surveying the field of animal rights, or animal welfare, that "[o]ur moral argument is that species alone is not a valid criterion for cruel discrimination.... Where it is wrong to inflict pain upon a human animal it is probably wrong to do so to a nonhuman sentient. The actual killing of a nonhuman animal may also be wrong if it causes suffering or, more contentiously, if it deprives the nonhuman of future pleasures. The logic is very simple." RYDER, supra note 6, at 6-7.

8. This is a central thesis of GARY L. FranCIONE, ANIMALS, Property, AND THE LAW (1995). See also Paola Cavalieri \& Peter Singer, The Great Ape Project-and Beyond, in THE GREAT APE Project, supra note 3, at 304; Gary L. Francione, Personhood, Property and Legal Competence, in THE GREAT APE PROJECT supra note 3, at 248.

9. According to Francione, the failure to attack the underlying legal problem of the legal status of animals as property will further delay improvements for animals. GARY L. FRANCIONE, RAIN Without THUNDER: THE IDEOlogy OF THE ANIMAL Rights MOVEMENT (1996). An alternative approach is suggested by David Favre. David Favre, A New Property Status for Animals: Equitable SelfOwnership, in ANIMAL RIGHTS, supra note 7, at 234-50 (advocating treating animals legally as a kind of property with legally cognizable interests). 
rights, both groups are referred to as "animals' advocates." Similarly, the term animal "(ab)use" is used to capture the perspectives of both those who think that only abuse in the use of animals need be addressed and those who think that all uses of animals constitute abuse and exploitation.

Part II discusses several problems with the similarity argument in the particular context of advocacy for animals. As a theory of justice for animals, the similarity argument makes the fact of diversity of nonhuman life irrelevant or actually harmful to animals because it undercuts the justification for protecting them-that they are like humans. Also, the similarity argument promotes pernicious hierarchical ordering of nonhuman animals based on their relative proximity to humans. As a pragmatic matter, it is extremely difficult to prove to the satisfaction of opponents that nonhuman animals are sufficiently like human animals that justice requires curtailing the rights that humans currently have in nonhuman animals. As in the case of chimpanzees' making tools, proof of animals' similarity to humans could as easily (if not more easily) result in redefining what it means to be human as it could result in redefining animals as part of the human community.

Part III considers two examples of other social justice movements that first used the similarity argument but later adopted a different ideological pathway to justice. That pathway is referred to as "the anti-discrimination approach" because it is based on the idea that a just society would prevent harm or exclusion that is based on superficial or irrelevant differences among people. Such a society would protect and amplify the values of diversity and inclusion. Borrowing to some extent from the precautionary principle, which developed in the context of environmental protection, the anti-discrimination stance requires restraint on the part of those who can, by virtue of their power to exclude or control others, cause harm to others, and it requires that those individuals or entities bear the burden of justifying exclusion or harm to the interests of others. As examples of the emergence of the anti-discrimination approach, Part III examines feminist advocacy for family and medical leave provisions and disability rights advocacy for greater accessibility to commercial and residential buildings.

Part IV discusses two examples of an anti-discrimination approach as applied to animal protection: the Endangered Species Act and the development of artificial wildlife corridors. Neither is an ideal example of the antidiscrimination approach. Nevertheless, each does reveal some aspects of the anti-discrimination approach and its advantages over the similarity argument. Those advantages include promoting respect for the diversity of animals, rather than having to prove their similarity to humans, shifting attention from animals' worthiness (or not) to be free from exploitation to supposed or proffered justifications for exploitation, and emphasizing advocacy to create an animalrespecting society without first having to prove that animals are like humans. In its most rigorous forms, the anti-discrimination approach leads to precautionary protection of animals without first waiting for harms to occur and subsequently 
seeking to correct those harms; it requires anticipatory accommodation of animal interests.

\section{II}

\section{PROBLEMS WITH THE SIMILARITY ARGUMENT}

The similarity argument, in the context of advocacy for animals, claims that animals are like humans in the capacities that are relevant to legal entitlements and, therefore, that a just society would provide species-appropriate legal entitlements that mirror the entitlements society gives humans. A fundamental problem with this argument is that it is not possible to resolve completely the question whether some or all animals are sufficiently like humans that justice requires treating the two groups alike, even if there were agreement about which capacities are relevant for comparison. ${ }^{10}$ Information about animals' capacities, independent of comparisons to human capacities, is useful information about animals and may change public attitudes about animals. Nevertheless, if the basis of the claim for increased protection is that like entities (humans and animals) should be treated alike (both should have entitlements to protect themselves), information about animals simply as animals (and not as compared to humans) is not useful for the purpose of giving animals increased protection and reducing the rights of humans to (ab)use them. If animals do not have characteristics considered essential to humans in the ways that those characteristics exist in humans, it is possible to dismiss claims of similarity raised for purposes of curtailing humans' use of animals. Even if one is seeking only better treatment for animals and not legal rights, the argument of similarity to humans is weakened by counterarguments that animals are not similar enough to create an obligation in humans to treat them better. For example, animals may feel pain but cognitively process it differently or manage it more effectively. ${ }^{11}$ Animals may think, but not in the ways that

10. In fact, there is disagreement about which capacities are relevant. See John Rawls, Outside the Scope of the Theory of Justice, in POLITICAL THEORY AND ANIMAL RIGHTS, 154, 155 (Paul A.B. Clarke \& Andrew Linzey eds., 1990) (contending that since animals lack a moral sense they are not owed the duties of justice). In some cases the disagreement is about what type of cognitive or sentient capacities animals share with humans that would justify the similarity argument. For example, Raymond Frey has argued that animals lack complex language, which indicates deficiencies in cognitive capacity as compared to humans. RAYMOND FREY, INTERESTS AND RIGHTS: THE CASE AGAINST ANIMALS (1980); see also STEPHEN WALKER, ANIMAL LEARNING: AN INTRODUCTION (1987). The idea that animals do not have language has been reconsidered on the basis of research since the time of these publications. See, e.g., Donald H. Owings \& Eugene S. Morton, ANimal Vocal COMMUNICATION: A NEW APPROACH (1998) (arguing that animals use verbal communication in order to cause others to do what they want them to do); EUGENE S. MORTON \& JAKE PAGE, ANIMAL TAlK: SCIENCE AND THE Voices OF NATURE (1992). However, the debate continues. See, e.g., DANIEL C. DENNETT, KINDS OF MINDS: TOWARD AN UNDERSTANDING OF CONSCIOUSNESS (1996).

11. See, e.g., Temple Grandin, ANimals In TRAnsLation 187 (2005) ("I think injured animals are probably somewhere in between a leucotomy patient and a normal human being. They do feel pain, sometimes intense pain, because their frontal lobes haven't been surgically separated from the rest of their brains. But they probably aren't as upset about pain as a human being would be in the same situation, because their frontal lobes aren't as big or all-powerful as a human's .... I think it's possible that animals may have as much pain as people do, but less suffering."); see also SHERRY, supra 
humans do. If an animal lacks self-consciousness or the cognitive ability to anticipate his life in the future, the loss of his life may be deemed less meaningful than the loss of a human's life because humans do have selfconsciousness and can project themselves into the future. ${ }^{12}$ Moreover, new information that appears to prove similarity between humans and animals may only result in a redefinition of the term "human" so that the oppositional categories of "human" and "animal" remain intact. Just as the finding that chimpanzees make tools meant that humans would no longer be defined by reference to toolmaking, newfound similarities between animals and humans may result only in new or refined definitions of humans, in order to retain the singularity of humans.

\section{A. Problems of Proof and Acceptance of Proof}

Given what is at stake if justice requires that like entities be treated alike, it is not surprising that it is difficult to prove or to gain acceptance of even basic similarities of animals with humans. As many as thirty-five years before Goodall's observation of chimpanzees making tools in the wild, Wolfgang Köhler documented the ability of captive chimpanzees to figure out how to stack boxes and to make poles long enough to obtain bananas placed out of reach. ${ }^{13} \mathrm{He}$ could not document what was going on in their minds,${ }^{14}$ however,

note 7, at 32, 38; Bob Bermond, The Myth of Animal Suffering, in THE ANIMAL ETHICs ReAdER 79 (Susan J. Armstrong \& Richard G. Botzler eds., 2003).

12. For example, even a strong advocate for animals, philosopher Tom Regan, has conceded that if four humans and one dog of equal weight occupy a lifeboat that can safely accommodate only four, the dog should be sacrificed because the dog, unlike the humans, does not live in anticipation of the future or understand what his loss will be. It doesn't help the dog that he can think; the dog has to think like $a$ human in order to be saved. See REGAN, supra note 6, at 324-25. According to Gary Francione, Regan's example of the lifeboat seems to be at odds with Regan's underlying theory of animal rights. Francione points out that there is a basic problem in using for conflict resolution among existing rightsholders a theory whose purpose is to establish the basic rights not to be exploited and killed at someone's whim. Gary Francione, Comparable Harm and Equal Inherent Worth: The Problem of Dog in the Lifeboat, 11 BETWEEN THE SPECIES 86, 86-88 (1995). My point here, though, is to acknowledge how easy it is to concede that since animals may not think like humans in all respects, they should be treated differently. If even an ardent advocate for animals can take that position, opponents could easily make use of it as well.

Another example of differentiation in animal and human thought is captured by Mary Ann Warren, who writes that non-human animals cannot change their behavior based on rational thought. Mary Ann Warren, Difficulties with the Strong Animal Rights Position, in ANIMAL EXPERIMENTATION: The MORAL IsSUES 89-99 (Robert M. Baird \& Stuart E. Rosenbaum eds., 1991). "We cannot negotiate a treaty with the feral cats and foxes, requiring them to stop preying on endangered native species in return for suitable concessions on our part." Id. at 95.

13. Wolfgang Kohler, The Mentality of APES (1925). Kohler's publication includes photographs of chimpanzees, including one of a chimpanzee named Sultan making a double stick out of two separate sticks. Id. at 132.

14. In striking deconstruction of Kohler's experiment, J. M. Coetzee writes a fictional rendition of the experiment on Sultan. In Coetzee's version, the chimpanzee wonders and "thinks" many things besides what the researcher is testing as his thought process. He may wonder about the man who used to provide food but who now hangs it out of reach. He may wonder about whether the man no longer needs the boxes he has put in the chimpanzee's enclosure. "At every turn Sultan is driven to think the less interesting thought. From the purity of speculation (Why do men behave like this?) he is relentlessly propelled towards lower, practical, instrumental reason (How does one use this to get 
and neither could Goodall as to the chimpanzees she observed. That is significant because once it was determined that chimpanzees could make tools, humans were no longer defined by reference to their toolmaking, but by reference to other cognitive abilities that chimpanzees and other animals had not been proved to have, such as self-awareness. Since then captive research chimpanzees have been anesthetized, marked, and then given mirrors in order to assess whether chimpanzees may have the human trait of "self-awareness," as indicated by the extent to which they recognize the value of mirrors in giving them information about their bodies. ${ }^{15}$ Much more painful and invasive research on cognition has been conducted, such as induction of blunt-force trauma to the skulls of chimpanzees to investigate the biodynamics of traumatic unconsciousness, and dissection of chimpanzees' facial nerves to measure nerve response to a chemical that blocks the taste of sweet substances. ${ }^{16}$

The cognitive abilities of many animals, not just chimpanzees, have been observed or tested, sometimes in quite painful and invasive procedures. ${ }^{17}$ Yet, despite all this research, the fact of animal consciousness and cognition is accepted generally only to the extent of recognition that some animals have qualities they were not previously thought to have. This may have enhanced sympathy and respect for some animals, but it has not resulted in acceptance of

that?) and thus towards acceptance of himself as primarily an organism with an appetite that needs to be satisfied.... In his deepest being Sultan is not interested in the banana problem. Only the experimenter's single-minded regimentation forces him to concentrate on it. The question that truly occupies him, as it occupies the rat and the cat and every other animal trapped in the hell of the laboratory or the zoo, is: Where is home, and how do I get there?" J. M. CoETZEE, ELIZABETH COSTELLO 73-75 (2003). Coetzee's deconstruction is important because it shows the limits of research into cognitive capacity. In fact, those limitations are exploited by opponents of increased animal protection when they claim that research shows only apparent similarity with humans and cannot document actual similarity with humans. We cannot know what Sultan, or any other animal, is actually thinking. If it could be proved that Sultan is actually thinking "where is home and how do I get there," it would be more difficult to refute the similarity argument.

15. Daniel J. Povinelli et al., Chimpanzees Recognize Themselves in Mirrors, 53 ANIMAL BEHAVIOR 1083, 1086 (1997). Understanding that an image in a mirror is a reflection of one's self is considered an important indicator of whether an animal has self-awareness. See NICHOLAS WADE, Who's that Strange Monkey in the Mirror?, N.Y. TIMES, July 26, 2005, at F3. As evidence that the animal is actually recognizing that the image is of herself, Dr. Franz de Waal of the Yerkes National Primate Research Center notes that female chimpanzees will look at the parts of their bodies they cannot usually see: the inside of their mouths and their rear ends. Id.; see also SELF-AwARENESS IN Animals and Humans: Developmental Perspectives (Sue Taylor Parker et al. eds., 1994). Recent research on elephants suggests that they, too, have self-awareness, as indicated by their use of mirrors. See, e.g., Joshua M. Plotnik, Frans B. de Waal, and Diana Reiss, Self-Recognition in an Asian Elephant, 103 PROC. NAT'L ACAD. SCI. 17053 (2006), available at http://www.pnas.org/cgi/reprint/ $0608062103 v 1$.

16. See, e.g., Ayub K. Ommaya et al., Head Injury in the Chimpanzee, Part 1: Biodynamics of Traumatic Unconsciousness, 39 J. NEUROSURGERY 152 (1973); G. Hellekant et al., Effects of Gymnemic Acid on the Chorda Tympani Proper Nerve Responses to Sweet, Sour, Salty, and Bitter Taste Stimuli in the Chimpanzee, 124 ACTA PHYSIOLOGICA SCANDINAVICA 399 (1985).

17. For summaries of research about the cognitive abilities of animals, see, for example, THE Cognitive ANIMAL: EMPIRICAL AND THEORETICAL PERSPECTIVES ON ANIMAL COGNITION (Marc A. Bekoff et al. eds., 2002); DonAld R. GRIFFIn, ANIMAL Minds (1992); JACQUES VAuClair, ANIMAL COGNITION: AN INTRODUCTION TO MODERn COMPARATIVE PSYCHOLOGY (1996); CLIVE D.L. Wynne, Animal Cognition: The Mental Lives of Animals (2001). 
such animals as similar enough to humans that they should be given the legal rights held by human rights-holders at the same level of cognitive capacity. ${ }^{18}$

Acceptance of the idea that animals can feel pain and experience emotions also lags, despite longstanding anecdotal evidence and observation-based research data that have documented intense and complex emotions in animals. ${ }^{19}$ Simple observations of animals' limping after an injury have not been accepted as sufficient to prove that animals experience pain. ${ }^{20}$ Thus, laboratory scientists have designed a variety of research protocols to address the question of animals' ability to feel pain. ${ }^{21}$ Even fish have received attention. For example, scientists have found that administering morphine to goldfish hinders the ability of goldfish to learn to avoid electric shocks ${ }^{22}$ and that fish subjected to apparently painful stimuli produce biochemical compounds similar to those produced by mammals in response to pain. ${ }^{23}$

Despite these types of findings, research conducted to determine the extent of animals' capacity to feel pain still leaves room for vigorous debate about what animals actually feel when they appear to suffer pain. ${ }^{24}$ Some argue that such research can only suggest what is going on in the minds of animals; it cannot prove definitively how the subject animals are cognitively processing apparently painful stimuli. ${ }^{25}$ This is more than a concern about the possibility of

18. Anstötz, The Great APE Project, supra note 5, at 169-70, 158-72.

19. Charles Darwin wrote extensively on the subject, believing that animals have emotions like those of humans. CHARLES DARWIN, THE EXPRESSION OF EMOTIONS IN MAN AND ANIMALS (3d ed., Oxford Univ. Press 1998) (1872). However, his views were rejected at the time. Subsequent research has revived the issue of emotions in animals. Jane Goodall's research documented the existence of strong emotions in chimpanzees. Goodall, supra note 1, at 357-87. It has also been documented in other animals. JEFFREY MOUSSAIEFF MASSON \& SUSAN MCCARTHY, WHEN ELEPHANTS WEEP: THE EMOTIONAL Lives of ANimals (1995) (elephants); MYrna M. Milani, THE Body LANGUAGE AND EMOTION OF DOGS (1986) (dogs); ALEXANDER F. SKUTCH, THE MindS OF BIRDS (1999) (birds).

20. In summarizing the research on animal pain, Temple Grandin describes the act of "pain guarding" in which animals will avoid putting weight on injured limbs, stating that "we think insects probably don't feel pain ... because an insect will continue to walk on a damaged limb." GRANDIN, supra note 11, at 183 . Kevin Dolan argues that although some have doubted that animals feel pain, pain and suffering are rampant in nature and that doubts about animal pain have been more a matter of ignoring the existence of animals' pain and being indifferent to it. KEVIN DOLAN, ETHICS, ANIMALS AND SCIENCE 155 (Iowa State Univ. Press 1999) (1989).

21. See Bernard E. Rollin, The Unheeded Cry: Animal Consciousness, Animal Pain, AND SCIENCE 114-18 (1998).

22. See Lynne U. Sneddon et al., Do Fishes Have Nociceptors: Evidence for the Evolution of a Vertebrate Sensory System, 270 BIOLOGICAL SCI. 1115 (2003).

23. Michael K. Stoskopf, Pain and Analgesia in Birds, Reptiles, Amphibians, and Fish, 35 INVESTIGATIVE OPHTHALMOLOGY \& ViSUAL SCI. 775 (1994).

24. See Ricki Lewis, Animal Models of Pain, THE SCIENTIST, Mar. 28, 2005, at S5, available at http://www.the-scientist.com/2005/03/28/S10/1\#top; see also William Timberlake, The Attribution of Suffering, in ANIMAL EXPERIMENTATION: THE MORAL IsSUES, supra note 12, at 71, 76 ("Both animal rights advocates and scientists want to reduce the suffering of others, but this cannot be done in any reasonable way until we agree on its nature, extent, and relative value.").

25. Animal welfare advocate Temple Grandin frames it this way: "I think the real question isn't whether or not animals (and birds and fish) feel pain. It's pretty obvious they do. The real question is how much does pain hurt? Does an animal with the same injury as a person feel as bad as a person does? We should be talking about degrees." GRANDIN, supra note 11, at 184. Clifford J. Sherry criticizes two leading proponents of animal protection, Tom Regan and Peter Singer, for failing to 
anthropomorphizing animals ${ }^{26}$ there is skepticism that scientific research can, at this point, fully investigate private, individual processing of experience by animals. $^{27}$

\section{B. Problems of Application}

Difficulty in proving similarity to humans and subsequent redefinition of humans when similarity is found are only two of several serious problems with the similarity argument. Use of the similarity argument inevitably creates a hierarchy of worthiness based on how closely an animal approximates the characteristics of humans, because the similarity argument posits that animals deserve protection comparable to that of humans only precisely in relation to how closely they approximate humans. Creation of hierarchy, especially by way of controlled scientific laboratory research to prove precise degrees of similarity, results in problems of line-drawing between and among animals.

Line-drawing and prioritizing some animals as more worthy of protection than others is the likely outcome of the similarity argument because it is unlikely that giving some entitlements to some animals, such as great apes,

distinguish between what he calls "sensation, perception, and the experience of pain." He claims that it is unlikely that animals experience pain as do humans (except for great apes and cetacea) because they lack the type of brain structures that permit processing of sensations humans process as pain. SHERRY, supra note 7, at 32,38. This is also the view of Bob Bermond. See Bermond, supra note 11.

This is not just a function of linguistic facility. Harvard research psychologist Daniel Gilbert has noted that it isn't possible fully to know the experience of humans even when they can express their thoughts very clearly.

How can we tell whether subjective emotional experiences are different or the same? The truth is that we can't-no more than we can tell whether the yellow experience we have when we look at a school bus is the same yellow experience that others have when they look at the same school bus.... [W] $\mathrm{Wen}$ all is said and done, the only way to measure precisely the similarity of two things is for the person who is doing the measuring to compare them side by side - that is to experience them side by side. And outside of science fiction, no one can actually have another person's experience.

DANIEL GILBERT, STUMBLING ON HAPPINESS 39 (2006).

26. Michael P.T. Leahy, Against Liberation: Putting Animals in Perspective (1991). Some see overstatement on both sides: activists making animals too human and scientists making animals too mechanical. See Deborah Blum, The Monkey WARS 264 (1994) (characterizing the position of Tom Gordon of the Yerkes Field Station). Another interesting perspective is that "anthropomorphism may not necessarily be false. The danger lies in assuming too readily that some animal attributes can be explained by reference to humans." ROBERT GARNER, ANIMALS, POLITICS AND MORALITY 35 n.1 (1993) (citing S.J. Vicchio) (emphasis added).

27. See, e.g., JAMES F. WitTenberger, ANimal Social Behavior 49 (1981) ("We cannot assume that animals make conscious decisions because we cannot monitor what goes on inside their heads."); see also Peter Harrison, Animal Pain, in ANIMAL EXPERIMENTATION: THE MORAL Issues, supra note 12, at 128, 129 ("No strict argument can be mounted for or against the existence of animal pain.... [I]t is the essence of pain that it is a private experience."); STEPHEN P. STICH, FROM FOLK Psychology to Cognitive SCIENCE: THE CASE AGAinst BEliEF 18 (1983). However, not knowing definitively what is going on in the private minds of others does not, by itself, justify causing animals pain. See, e.g., Marc Bekoff, Common Sense, Cognitive Ethology and Evolution, in THE GREAT APE PROJECT, supra note 3, at 102; Donald Davidson, Rational Animals, in ACTIONS AND EVENTS: PERSPECTIVES ON THE PHILOSOPHY OF DONALD DAVIDSON 473 (1985); GRIFFIN, supra note 17, at 117. 
would, by itself, break down resistance to giving rights to other animals. ${ }^{28}$ Because humans have strong interests in keeping the comparably protected community small, humans would not be likely to expand the reference point to include great apes for purposes of examining other species to determine their similarity to current rights-holders (humans and great apes). Humans would most likely continue to use themselves as the exclusive reference point for establishing similarity for purposes of the similarity argument. Just as close attention to similarities and dissimilarities between great apes and humans would be the origin of rights for great apes, each species of animals would have to undergo comparison to humans, and each animal species would have to be found sufficiently similar to humans that justice would require each species to receive comparably protective treatment. ${ }^{29}$ Advocates for animals may seek to restructure society to end and prevent exploitation of animals (for example, ending animal flesh-food consumption), ${ }^{30}$ but use of the similarity argument for that purpose is arduous, at best, until the last apparently exploitable, edible animal is proved to be similar enough to humans to merit protection. Since, despite decades of research, we have not yet proved sufficient similarity between humans and great apes-with whom we share the closest evolutionary relationship-just how likely is it that we will prove sufficient similarity between humans and cows, humans and pigs, humans and sheep, humans and rabbits, humans and chickens, or humans and fish?

In the hierarchy created by the similarity argument, humans would occupy the top position in the hierarchy because humans are the standard against which other animals are measured. Human-made hierarchies already exist, such as

28. Theoretically, other animals could become rights-holders as a result of great apes' first being given rights, if great apes were to receive (through their legal representatives) the right to confer rightsholding status on other animals. Though theoretically possible, it is implausible that apes will receive the means by which other animals would be included-voting rights exercised by their human representatives. Opponents use the example of giving animals the right to vote to demonstrate the absurdity of an animal rights perspective, but, to date, no animal rights advocate appears to have made the claim that animals should have the right to vote. In fact, some have expressly stated that the entitlements for which they advocate do not include voting rights. See, e.g., GARY L. FRANCIONE, Introduction to Animal Rights 101 (2000); Steve F. Sapontzis, Aping Persons-Pro and Con, in The Great APE Project, supra note 3, at 269, 274; Peter Singer, Ethics Beyond Species and Beyond Instincts: A Response to Richard Posner, in ANIMAL RIGHTS, supra note 7, at 78, 79; Cass R. Sunstein, Introduction: What Are Animal Rights?, in ANIMAL RIGHTS, supra note 7, at 3,11.

29. See generally STEVEN M. WISE, DRAWING THE LINE: SCIENCE AND THE CASE FOR ANIMAL RIGHTS (2002) (discussing the possibility of including animals in the protected circle as documentation about their abilities and capacities becomes available).

30. Consuming animals while professing respect for them is controversial. For example, although Peter Singer states that "practically and psychologically it is impossible to be consistent in one's concern for nonhuman animals while continuing to dine on them," he leaves open the question of consuming animals if they are actually humanely raised and killed, stating that only if animals were humanely treated before killing them for consumption would we get to that question. SINGER, supra note 6 , at 164 . "Whatever the theoretical possibilities of rearing animals without suffering may be, the fact is that the meat available from butchers and supermarkets comes from animals who were not treated with any real consideration at all while being reared. So we must ask ourselves, not: Is it ever right to eat meat? But: Is it right to eat this meat?" Id. at 165. Another philosopher, Roger Scruton, argues that consuming animals demonstrates respect for them. Roger Scruton, A Carnivore's Credo, HARPER'S MAGAZINE, May 2006, at 21. 
those based on how cute animals are, whether we want to eat them, and whether they hold some symbolic value for us (for example, eagles representing majesty and snakes representing evil). Those hierarchies, unlike the hierarchy generated by the similarity argument, did not result from attempts to help animals. Yet, even though the origins of the similarity argument lie in an effort to help animals, the hierarchy created by its application can cause harm in two ways. First, it creates a priority of protection of only certain animals when, in fact, all animals exist interdependently and each is important to sustaining the web of life in which we all live. Two hypothetical letters written by Richard Dawkins in his contribution to The Great Ape Project provide the basis for illustrating how the similarity argument creates a hierarchy based on prioritizing the protection of animals most similar to humans. ${ }^{31}$ In the first letter, the writer rejects advocacy for gorillas until the needs of every child have been addressed. In the second, the writer rejects advocacy for gorillas until every aardvark has been saved. Dawkins contrasts the two letters, noting that the first is completely plausible because the oppositional categories of animals and humans replicate our society's belief that animals have less value than humans. The second letter is not plausible because both subjects of the second letter are animals, and both subjects (not being human) fall into the less valued category. However, advocacy on the basis of similarity would create a hierarchical ordering of animals in relation to their similarity to humans. Then it would be plausible for a writer to prioritize assistance to one animal species (aardvarks) before another (gorillas). ${ }^{32}$ Yet, while humans are prioritizing one animal over another, animals are living in an interdependent world in which all animals, regardless of their similarity to humans, need protection. ${ }^{33}$

Second, hierarchical ordering of animals based on their similarity to humans would increase harm to dissimilar animals by facilitating exploitation of dissimilar animals for the benefit of animals deemed to be like humans. ${ }^{34}$

31. Richard Dawkins, Gaps in the Mind, in ThE GREAT APE PROJECT, supra note 3, at 80, 80-81.

32. Since the hierarchy would privilege those deemed closer to humans, Dawkins' second hypothetical letter about gorillas versus aardvarks would probably be written differently to prioritize protection of gorillas over aardvarks. Unless science shows us that aardvarks are closer to humans than are gorillas as to capacities considered essential to being human, the argument will be that gorillas should be fully protected before investing effort in protecting aardvarks.

33. I have examined this idea in more detail in Taimie Bryant, Animals Unmodified: Defining Animals/Defining Human Obligations to Animals, 70 U. CHI. LEGAL F. 133 (2006).

34. Catherine MacKinnon has considered both problems of (1) the similarity argument and (2) hierarchy. As to the former, she noted that "seeking animal rights on a 'like-us' model of sameness may be misconceived, unpersuasive, and counter-productive" because it "misses animals on their own terms, just as the same tradition has missed women on theirs." Catherine A. MacKinnon, Of Mice and Men: A Feminist Fragment on Animal Rights, in ANIMAL RigHTS, supra note 7, at 263, 264. As to the latter, MacKinnon invokes the problem of hierarchical ordering of beings, which, in her view, may be especially pernicious when verbiage about love and protection mask domination. Id. at 264-65.

Prior to MacKinnon's recent contribution to the debate, a substantial amount of feminist literature critiqued giving animals rights, but it was not a critique primarily of the similarity argument. It was an argument based on the idea that rights themselves-however justified-create hierarchies that then further the opportunity for domination and oppression by those higher up in the hierarchy of rights entitlements. See, e.g., Marti Kheel, The Liberation of Nature: A Circular Affair, in BEYOND ANIMAL 
Exploitation of animals for the sake of other animals already occurs as, for example, when humans feed (and over-feed) their companion animals pet foods made from factory-farmed animals. The hierarchy derived from application of the similarity argument provides yet another basis for exploitation. If entitlements flow from a determination by humans that a species of animal is similar to humans, to assure receipt of such entitlements, the law granting rights would provide for human representatives to act on the animals' behalf. If, for example, sea lions were found to be sufficiently similar to humans that justice required their receiving entitlements, their representatives surely would try to safeguard the health of sea lions by securing for them all the fish they need, which would most likely mean increasing the production of fish by intensive fish-farming. ${ }^{35}$ Overall consumption of fish would increase, so that no sea lion would be undernourished, which occurs now when sea lions must do their own fishing. Sea lions-via their human representatives ${ }^{36}$ - would thereby add to the exploitation that fish already experience at the hands of humans. ${ }^{37}$ This assumes

Rights: A FEMINIST CARING ETHIC FOR THE TREATMENT OF ANIMALS 17, 29 (Josephine Donovan \& Carol J. Adams eds., 1996) ("The notion of rights can, in fact, be conceived of only within an antagonistic or competitive environment."); see also Deane Curtin, Toward an Ecological Ethic of Care, in BEYOND ANIMAL RIGHTS, supra, at 60, 64 (noting that "the rights approach ... is inherently adversarial"). The claim in this paper is that a hierarchy is created directly through the similarity argument and is not necessarily derivative of rights.

35. Sea lions are chosen as an example here because sea lions must eat fish to survive. A somewhat different example is that of bears, who are omnivorous and like to eat fish. Arguably, if bears were deemed sufficiently similar to humans, then their apparent preference to maintain their health by eating fish should guide their human representatives' selection of their diet. So, even if bears could manage to survive without eating fish, why shouldn't they eat fish as they like, as do humans (to whom they are similar)? Likewise, why should sea lions not be able to eat all the fish they want (not limited by need to safeguard health) if they are similar enough to humans that justice requires treating them like humans (who eat all the fish they want irrespective of health)?

36. Perhaps it could be said that giving sea lions entitlements comparable to humans leads to humans' exploitation of fish on behalf of sea lions instead of sea lions themselves exploiting animals. However, the point remains that giving sea lions entitlements has resulted in greater exploitation of fish, regardless of who is engaging in the exploitation. If sea lions (through their human representatives) are not allowed to exploit fish through intensive fish-farming, then they have not been given entitlements comparable to humans, who can exploit fish freely.

37. Although packaging and advertising claims may lead consumers to believe that farmed fish are raised in idyllic circumstances in which they are protected from predators and fed a diet they enjoy (for purposes of fattening them for human consumption), in actuality farming of fish most often involves raising fish in overcrowded and dirty conditions with heavy dosing of antibiotics as the means of controlling the consequences of those conditions. Fish still suffer from various infections and parasitic predation. In the course of describing injuries and diseases to which salmon are susceptible in intensive fish-farming, Stephen Hume quotes two scientists as follows:

Everywhere I went near the farms, the fish were covered with sea lice when I took them out of the water.... Coho smolts were so frantic to escape the sea lice that they were jumping into boats. I noticed bleeding at their eyeballs and bleeding at the base of the fins, which are classic symptoms of fish disease. I was horrified to see these baby fish being ravaged by these parasites .... (Quoting Alex Morton)

Anybody who isn't moved by the grotesque image of those baby salmon being eaten alive by these sea lice - their little eyes popping out because the lice have eaten right through their heads ... well, that person probably can't be moved. (Quoting Chris Bennett)

Stephen Hume, Fishing for Answers, in A STAIN UpOn THE SEA: WeSt COAST SALMON FARMing 2425 (2004). 
that fish had not been granted entitlements at the same time as sea lions, which is likely if similarity to humans is the basis for deciding which species shall be admitted to the community of those protected by application of the justice argument that like entities be treated alike. If the approach to law reform for animals is not premised on similarity to humans but is premised instead on respect for diversity of life, then sea lions and fish would be equally situated at the same point in time.

If a finding of similarity to humans does not result in entitlement to safeguard health as in the previous example, but results only in the entitlement not to experience direct, human-caused suffering, then humane exploitation that does not cause suffering should be sufficient, and the consumption of animals should pass moral muster as long as animals do not suffer as they are turned into human-consumption goods. ${ }^{38}$ But, if animals really are like humans as to essential characteristics, why is it just to allow animals only the limited entitlement of freedom from human-caused suffering when humans have far more extensive entitlements? Why should they not also have rights of selfactualization? If one responds that animals' entitlements should be limited because they are not exactly like humans, then one has undercut the similarity argument altogether: opponents can readily claim that animals and humans are not actually so much alike that justice requires treating the two groups alike in any respect.

Those and other rather tedious questions arise because the similarity argument is not self-limiting as to what it means to be "treated alike" and because application of the similarity argument inevitably creates a hierarchy of animals such that it becomes necessary to sort out relative entitlements among animals. One wonders if animals would prefer that we spend our time on such questions when, after all, the similarity argument does not even provide a means for answering the questions it raises. For instance, mere inclusion of animals in the moral community does not provide a basis for resolving disputes between and among community members about access to increasingly scarce resources, such as clean water, air, and habitat, unless one uses the crude measure of preferring those animals who approximate humans the most closely. If approximation to humans is the basis upon which such disputes would be

Fish suffer injuries and oxygen deprivation due to crowding and poor water quality. Although there are various means for killing fish for production, few of them take account of the capacity of fish to suffer. For example, most trout farmers use the least expensive method: slow suffocation that results from removing the oxygen supply. There are also species-specific torments. For example, according to a diver who works for salmon farms that keep salmon crowded into sea cages, salmon suffer if they are not killed "before their migratory instinct kicks in." See Andrew Purvis, Farmed Fish, OBSERVER, May 11, 2003, at 20, available at http://observer.guardian.co.uk/foodmonthly/story/0,,951686,00.html; see also, Terry McCarthy \& Campbell River, Is Fish Farming Safe?, Time, Nov. 17, 2002, Bonus Section, http://www.time.com/time/globalbusiness/printout/0,8816,391523,00.html (describing problems associated with aquaculture, which include harms to the environment and harms to wild fish as well as harms to intensively farmed fish).

38. This may be a basis for distinguishing those advocates who seek only humane use of animals and those advocates who seek an end to humans' use of animals altogether. 
resolved, the situation would not be very different for animals than it is now: without entitlements in resources, animals currently lose in contests with humans over those resources because they have no power; with entitlements in resources, animals would still lose in contests with humans over those resources because their entitlements would receive lower priority than those of humans. ${ }^{39}$

Use of the similarity argument also creates tension with one of the goals of animal advocacy: freeing animals from exploitative research. ${ }^{40}$ Whether the advocate seeks rights for animals or only more humane treatment, the similarity argument requires advocates to use the results of animal-based research in order to claim that animals are similar enough to humans to justify the legal protection they seek on behalf of animals. Whatever one's view about whether there are risks to animals associated with research based on observations of animals in their own habitats, such observation-based research is easily challenged when legal entitlements are at stake. Since this society places a premium on data from "controlled" laboratory experiments, both advocates and opponents will have incentives to use data drawn from research on captive animals. If observations of animals apparently reacting to pain by avoidance or limping have been insufficient to prove that animals experience pain in the same way that humans do, every proposed similarity of animals to humans will be subjected to testing through laboratory research. ${ }^{41}$

That advocates can cause painful research to be conducted on animals is illustrated by advocates' efforts to ban the production and sale of foie gras in California. ${ }^{42}$ Videotapes of ducks and geese, forcibly fed for the production of foie gras, were used to demonstrate the suffering those animals experience, but opponents of the ban argued that the images in the videotapes were misleading because ducks and geese have esophagi that enable them to withstand forcefeeding without ill effect and that migratory birds gorge themselves naturally prior to migration. ${ }^{43}$ The (literal) picture of cruelty was significantly muddied in

39. "Similar" animals could receive equal priority if it is possible to increase the resource. For example, sea lions could be given equal entitlements to fish if fish-farming could be intensified to meet the demands of both humans and sea lions. However, if further intensification is not possible and sea lions' entitlements are inferior to those of humans (because they are less like humans than humans), then sea lions will lose in the contest for the scarce resource of fish.

40. Harold Guither briefly discusses various positions within the animal protection movement as to animal research. HAROLD D. GUITHER, ANIMAL RIGHTS: HISTORY AND SCOPE OF A RADICAL SOCIAL MOVEMENT 16-20 (1998).

41. See supra text accompanying note 20.

42. CAl. Health \& SAFETY CODE $\$ \S 25980-84$ (2005).

43. Kim Severson, Plagued by Activists, Foie Gras Chef Changes Tune, S.F. CHron., Sept.17, 2003, at A14. Scientists have also been involved in Europe. In response to pressure from other E.U. countries that oppose "provid[ing] food or liquid in a manner... which may cause unnecessary suffering or injury," the foie gras lobby in France produced the report of a committee of "eminent scientists from the National Veterinary School and the State Agricultural Research Institute" claiming that "the birds cannot be being cruelly treated because they are neither ill, over-stressed or even over-fed." Jon Henley, France Defies EU to Continue Force-Feeding Birds for Foie Gras, THE GUARDIAN (LONDON), Sept. 18, 2004, at 17, available at http://groups.google.com/group/AR-News/browse_thread/thread/ a14fa01eb073b117/1f8618ee2dcb5c2a?\#1f8618ee2dcb5c2a. 
debate..$^{44}$ Ultimately, the legislation was enacted when the only producer in California withdrew his objections to the legislation in return for (1) legislative immunity from a pending lawsuit alleging cruelty and any other such lawsuit for the next seven and one-half years, ${ }^{45}$ and (2) the opportunity to conduct research sufficient to prove that foie gras production is not inhumane. ${ }^{46}$

Advocates' participation in a process of argumentation that results in invasive, controlled laboratory experimentation on animals is problematic because so much research involves considerable deprivation and pain. Also, individual animals brought into experimental settings cannot meaningfully consent to participate in an experiment for purposes of proving their similarity to humans, and their lives are spent (usually quite literally) in the pursuit of an idea of "chimpanzeeness" or "goldfishness" or "animalness." ${ }^{47}$ They are

44. Upon hearing testimony presented by both sides as to the cruelty (or not) of forcibly feeding birds to enlarge their livers up to ten times their normal size, a legislator commented that the truth was hard to discern. "If we listen to these conversations, somebody is not telling the truth." California State Senator Edward Vincent, quoted in Jordan Rau, Activists Win One in Battle Over Pate Foie Gras, L.A. TIMES, Apr. 7, 2004, at B1.

45. CAL. Health \& SAFETy CODE $\S 25984(b)$.

46. See id. at $\S 25984$ (c). The language actually reads, "It is the express intent of the Legislature, by delaying the operative date ... to allow a seven and one-half year period for persons or entities ... to modify their business practices." Id. However, the producer who eventually agreed to the legislation and the Governor understood that the ban could be lifted without modification of business practices if the producers can show that current methods were not inhumane. See Carolyn Jung, Study Could Disrupt Planned Foie Gras Ban, SAn JOSE MerCuRY News, Oct. 27, 2004, at 15A, available at http://groups.google.com/group/soc.culture.indian/browse_thread/thread/7feb149559184777/08b9b91b2 842b7a8?\#08b9b91b2842b7a8; see also Ali Bay, Activists Unhappy with Foie Gras Law, CAPITAL PRESS, Oct. 11, 2004, available at http://groups.google.com/group/AR-News/browse_thread/thread/ c3f6f56c2e1224cd/a0ddb78d91df127e?\#a0ddb78d91df127e; Mike Dunne, Foie-Gras Ban Isn't All Bad, Supplier Says, SACRAMENTO BEE, Oct. 6, 2004, at F1, available at http://infoweb.newsbank.com/iwsearch/we/InfoWeb?p_action $=$ doc $\&$ p_docid $=105930$ C70CA0DFED\&p_docnum $=6 \&$ p_queryname $=5 \&$ p_product $=$ NewsBank\&p_theme $=$ aggregated4\&p_nbid=Y6EW59UOMTE2MjM0MjU3NC43Mzk2M DI6MToxMzoxNTIuMy4xNTAuMTYx; Dave Richardson, Foie Gras Feels the Heat, TIMES HERALDRECORD, Oct. 13, 2004, at 6, available at http://groups.google.com/group/AR-News/browse_thread/ thread/7983ce3a2e2682b8/e7172985f56825eb?\#e7172985f56825eb.

47. Feminists interested in animal protection have noted the problem of objectifying animals because their work on objectification of women has sensitized them to the perils of objectification generally. Objectifying animals, rather than viewing them as individuals, leads to their abuse. As Josephine Donovan and Carol J. Adams have written, "one of the main sources of the continuing atrocious abuse of animals by humans is an attitude that allows their reification or objectification." Josephine Donovan \& Carol J. Adams, Introduction, in ANIMALS AND WOMEN: FEMINIST TheORETiCAl EXPlorations 1, 7 (Carol J. Adams \& Josephine Donovan eds., 1995). Such objectification happens unwittingly as when, for example, abuse against animals is seen as a warning sign of the possibility of domestic violence occurring in a household. The abuse of the animal is, itself, also domestic violence in which the animal is a victim, not just a warning signal. See CAROL J. ADAMS, NeITHER MAN NOR BEAST: FEMINISM AND THE DEFENSE OF ANIMALS 144-61 (1994). In the context of experiments designed to evaluate the abilities of animals, what is valued in the research animals is what they will represent on the basis of data collected in the experiment, not who they are as individuals with idiosyncratic features. Animals subjected to research are objects known, on some level if not all levels, to the researcher as "research subjects" or representative chimpanzees rather than as individuals who happen to be chimpanzees. Moreover, their species having been objectified through the process of research experimental design and reporting, individual future animals may, but only "may," be protected by way of what is good for the class. Novelist J.M. Coetzee poses the problem by putting it into a hypothetical thought process of Sultan, one of the chimpanzees Wolfgang Kohler evaluated as to chimpanzee capabilities: "somehow, as [Sultan] inches through this labyrinth of constraint, 
unwilling participants in the creation of an objectified view of animals; they are not willing participants in research for the purpose of finding out about their own individuality or the diversity within their species. As the work of Carol J. Adams documents as to both women and animals, turning women and animals into objects is an integral part of the mindset that leads to their commodification and exploitation. ${ }^{48}$

Finally, how animals are characterized as similar to humans has significance in a society that values certain traits in humans and devalues others. For example, when advocates make the claim that animals are similar to humans as to human cognitive abilities, they are at least keying into a value that is desired and respected in this society. Entrance to the human community on the basis of a quality that is widely valued more readily sets the stage for respect than does entrance to the community on the basis of the capacity to suffer. When advocates claim that animals are similar to humans as to the capacity to suffer, they may at best be stimulating some humans to feel empathy for animals. But they also run the risk of provoking disdain, since the capacity to suffer is a quality that many see as a source of weakness in themselves or in humans generally. Entrance to the human community on that basis is entrance on the basis of a quality, which, if used as a definitive characteristic, may well lead primarily to pity and advocacy that seeks only the avoidance of animal suffering. ${ }^{49}$ Finally, proving the similarity of animals to humans as to the

manipulation and duplicity, he must realize that on no account dare he give up, for on his shoulders rests the responsibility of representing apedom. The fate of his brothers and sisters may be determined by how well he performs." COETZEE, supra note 14 , at 74 .

48. See generally Carol J. Adams, The Sexual Politics of Meat: A Feminist-Vegetarian CRITICAL THEORY (1990) (describing the analogous socio-cultural processes by which both women and animals become "absent referents" that promotes turning them into objects for exploitation).

49. All one gains from focusing on suffering is more humane exploitation so that animals will not suffer, or suffer less, as they are used for human purposes. In order to gain affirmative entitlements for animals so that they can lead lives protected from interference, one must make additional arguments and not rely exclusively on the capacity of animals to suffer.

The politics of pity and identity, borne of a focus on suffering, was raised by Elizabeth Spelman in her book Fruits of Sorrow, which explores how white women abolitionists of slavery used the suffering of enslaved women as a rallying cry for and definer of enslaved women. According to Spelman, an advocacy focus on suffering allowed white women to comfort themselves with the thought that, after all, they did not have things nearly as bad as enslaved women, and it promoted a flat, uninspiring picture of enslaved women who deserved pity but not respect. ELIZABETH SPELMAN, FRUITS OF SORROW (1997).

The potential for suffering and questions of actual suffering have informed the disability rights movement, as well. Disability rights advocates are quick to criticize characterization of people with disabilities as "suffering a disability" that makes their lives less fulfilling or, even, less worth living. Consider, for example, the many negative responses of the disability rights community to the apparent message in the movie MILLION DOLLAR BABY that a person with disabilities may be better off dead and that it is moral to assist him or her in dying. See Sharon Waxman, Groups Criticize 'Baby' for Message on Suicide, N.Y. TIMES, Jan. 31, 2005, at E2. Peter Singer also received tremendous criticism for comparing the value of life for a human with disabilities and a healthy animal. See HARRIET McBryde Johnson, Too Late to Die Young: NeARly True TAles From a Life 201-28 (2005). Finally, Dick Sobsey suggests that parents who kill their disabled children are treated more leniently legally because of a belief that such children were better off dead. See Dick Sobsey, Father's Day 2000, RAGGED EDGE ONLINE (2000), http://www.raggededgemagazine.com/extra/fathersday.htm. 
capacity to suffer creates incentives to conduct experiments specifically designed to induce terrible suffering in animals. For purposes of defining animals, that data may swamp research data focusing on other qualities of animals such that the primary information we have about animals concerns the ways in which they suffer. The symphony of animals' many wondrous capacities will be drowned out by the monotonous single note of their capacity to suffer. For all these reasons, particular care is warranted when one invokes the capacity to suffer or vulnerability to suffering as a justification for increased protection.

Use of the similarity argument as to single, discrete attributes of animals, such as the capacity to suffer, has been rejected by some. Philosopher Mary Midgley has argued that neither humans nor nonhumans can be defined by a single or even a few characteristics. ${ }^{50}$ More recently, both James Rachels and Martha Nussbaum have written in support of a more sophisticated view of animals, which includes respect for animals in accord with their complex abilities and ways of living in the world. ${ }^{51}$ Although much richer and more respectful of animals than single-characteristic line-drawing exercises, emphasis on complexity conflicts with the similarity argument.

The similarity argument that justice demands like treatment of like entities requires advocates to focus on animals' similarity to one or a few very specific human characteristics that are important to the definition of humans. At first glance, it may not seem that the similarity argument forecloses discussion of diversity. In the context of the argument that justice requires like entities to be treated alike, advocates could (and do) portray humans as so diverse that a spectrum of, say, consciousness exists that would include animals at various points along the spectrum occupied by humans. ${ }^{52}$ However, opponents have two

If a person with disabilities is seen as "suffering a disability" or as having enhanced future prospects of suffering, the abilities they do have and the joys they do experience can become background music, while paternalism and pity may well predominate in the foreground. Yet there is inevitable ideological and pragmatic difficulty because of opponents' demand that advocates demonstrate need sufficient to justify increased access. That problem is discussed in the next section. At this point, I note only that this is a difficulty that emerges in the context of having to compare supplicants for increased legal protection to existing rights-holders and that the choice of suffering as an identity-definer is problematic.

50. See MARy Midgley, BeAst And MAN 203-207 (1980) ("What is special about each creature is not a single, unique quality but a rich and complex arrangement of powers and qualities, some of which it will certainly share with its neighbors. And the more complex the species, the more true this is. To expect a single differentia is absurd.").

51. See Martha C. Nussbaum, Beyond "Compassion and Humanity": Justice for Nonhuman Animals, in ANIMAL RigHTS, supra note 7, at 299; James Rachels, Drawing Lines, in ANIMAL RigHTS, supra note 7 , at 162 .

52. Advocates for animals occasionally compare animals to humans who are young or humans who are impaired by age or disability. This has been called "the argument from marginal cases." According to one observer of the animal rights movement, this is "probably the most debated [argument] in the literature." GARNER, supra note 26, at 14-16. Perhaps the reason it is so debated is that it is a rendition of the similarity argument that spells out and seeks an answer to the uncomfortable question of treating animals so badly when they have qualities equal to or superior to the qualities of some humans. For a review and consideration of various positions on the argument, see DANIEL A. DOMBROWSKI, BABIES And Beasts: The ARgument from Marginal Cases (1997). More recently, philosopher Jeff 
responses at their disposal. They can reply either (1) that there is no spectrum for definitional purposes because humans are defined by reference to the consciousness of a mentally competent adult human being ${ }^{53}$ or (2) that there is a spectrum but that animals fall clearly outside of it. ${ }^{54}$ Advocates may try to preserve respect for the rich diversity of animal life by supplementing the similarity argument with evidence of that diversity. Yet, doing so is counterproductive to use of the similarity argument because emphasizing diversity undercuts the claim that animals are so like humans that justice requires treating them as such. If advocates themselves point to a more complex reality, the complexity of the reality can be used by opponents to obfuscate the issue of similarity to humans. Moreover, a focus on the similarity of animals to humans cannot but devalue the unique meaning that animals, in light of their wonderful diversity, bring to the concept of life, because it is only on the basis of similarity to specific characteristics of humans, and not on the basis of the tremendous diversity of animals at the individual or species level, that animals are deemed worthy of protection at all.

In summary, use of the similarity argument is problematic because, given what is at stake, it is extremely difficult for advocates to prove sufficient similarity. The similarity argument requires accumulating data from controlled research on animals even as advocates deplore research on animal subjects; and, despite voluminous evidence of similarity, proof of similarity can as easily lead to redefinition of humans as it can lead to redefinition of animals. To define animals in relation to human characteristics is not respectful to animals because it implies that their worth is measured by reference to how they compare to humans, and defining them by reference to the capacity to suffer is particularly hazardous to animals. The similarity argument generates a hierarchy for prioritizing the protection of animals when, in fact, all animals, including humans, need for all animals to be protected in order to sustain the web of life on which we all depend. As the sea lion and fish example illustrates, the hierarchy created by similarity also allows for privileged animals to join privileged humans in exploiting less privileged animals.

Finally, as long as the similarity argument is in play, the focus of debate about the exploitation of animals will remain on the worthiness of animals to be

\footnotetext{
McMahan takes on this problem of "marginal cases" in the specific context of killing by considering factors that affect decisions to actively or passively kill individuals, including animals, humans in vegetative states, and anencephalic infants. See JEFF MCMAHAn, THE ETHICs OF Killing: Problems AT THE MARGINS OF LIFE (2002).

53. See GARNER, supra note 26, at 15 . The more difficult case is that of people with permanent disabilities as compared to completely healthy, neurotypical animals. Again, the template of a typical adult human being may be asserted as the relevant standard, but others have argued that treating similarly animals and adults with disabilities in some circumstances is rational. See, e.g., R.G. FREY, RIGHTS, KILLING, AND SUFFERING (1983); JOHNSON, supra note 49, at 201-28 (revealing the views of Peter Singer in an interview with Johnson); see also DOMBROWSKI, supra note 52; MCMAHAN, supra note 52 .

54. This includes the argument described earlier that animals may appear to think or appear to suffer but they are actually not thinking or feeling pain the way humans do. See supra text accompanying note 25 .
} 
protected rather than on what a non-animal-consumptive society would look like or how we can get there. Compared to descriptions of animal exploitation and the injustice of exploiting animals so like humans, there are relatively few discussions and debates about what specific rights animals would have, other than not being property, or what an animal-respecting society would actually look like. This is not just a function of advocates' difficulty in stepping far enough outside the framework of their society's extensive use of animals to imagine a different societal relationship to animals. If, as a prerequisite to change, advocates are preoccupied with proving that animals are like humans, that preoccupation will deter and delay the development of concrete, detailed strategies for moving our society in the direction of valuing animals for the diversity of life they represent and for their unique qualities.

Since the similarity argument requires advocates to spend so much time defending their characterization of animals as "like humans," advocates may not have the opportunity to press the deepest and hardest questions of exploiters' moral entitlement to (ab)use animals. The similarity argument places advocates in a defensive posture when they could best serve the interests of animals by remaining focused on exploiters' justifications and rationales. By what moral entitlement do exploiters (ab)use animals in specific cases? By this question I do not mean philosophical, economic, religious, and legal reasons humans give for exploiting animals as a general matter. ${ }^{55}$ I mean challenging both exploiters' (ab)use of animals and the purported justification for such (ab)use in specific instances. I also mean placing the burden of justification on those who wish to harm animals.

A good example of this type of advocacy is The Paw Project's sponsorship of legislation that challenged the right of humans to declaw their cats for such purposes as protecting furniture..$^{56}$ Declawing is a drastic, extremely painful procedure that involves removing the last joint of each of a cat's toes. ${ }^{57}$ In

55. Legally, the explanation is that animals are the private property of humans. See FRANCIONE, supra note 8. Other justifications may be philosophical, economic, or religious, such as a belief that God made animals for the use of humans. See Aristotle, Animals Are for Our Use, in POLITICAL THEORY AND ANIMAL RIGHTS, supra note 6, at 56, 56-58 (arguing that animals by nature are inferior and require the governance of humans); St. Augustine, Rational Domination, in POLITICAL THEORY AND ANIMAL RIGHTS, supra note 6, at 59, 60 ("[B]y the just appointment of the Creator [animals are] subjected to us to kill or keep alive for our own uses...."); St. Thomas Aquinas, Unrestricted Dominion, in POLITICAL THEORY AND ANIMAL RIGHTS, supra note 6, at 60, 61 ("Wherefore, as man, being made to the image of God, is above other animals, these are rightly subjected to his government.").

56. The Paw Project sponsored legislation to ban declawing at the municipal level and at the state level in California. In 2004, California banned the declawing of wild and exotic cats. West Hollywood's ban was challenged by the California Veterinary Medical Association, which claimed that the city lacked legal authority to regulate the veterinary medical profession's use of veterinary medical procedures. The California Superior Court of Los Angeles agreed. Cal. Veterinary Med. Ass'n v. City of West Hollywood, No. SCO84799 (L.A. County Sup. Ct. filed Dec. 20, 2005). That decision is now pending on appeal. The record of the appeal is available at http://appellatecases.courtinfo.ca.gov/ search/case/mainCaseScreen.cfm?dist=2\&doc_id=187811\&doc_no=B188723 (last visited Feb. 20, 2007).

57. Onychectomy is the veterinary medical term for the procedure in which an animal's toes are amputated at the last joint. Amputation is necessary because the claw, unlike a human fingernail, is 
addition to detailed descriptions of the declawing procedure and its effects on cats, the Paw Project focused on unique or dissimilar features of cats from humans, such as differences between cats and humans as to the function of toes in balance, walking, jumping, climbing and running. ${ }^{58}$ Due to The Paw Project's advocacy, in 2003 the City of West Hollywood, California, banned declawing of cats. $^{59}$ Whereas previously owners could have their cats declawed without justifying their action, declawing is now disallowed unless it is medically necessary to preserve the cat's well-being. ${ }^{60}$ Thus, the legislative process enabled advocates to challenge and defeat common justifications of the declawing procedure, which were entirely unrelated to feline welfare, and to shift the burden of justifying the procedure to those who formerly had no such burden.

Advocacy designed to shift the burden of justification to those who formerly had no such burden has been developed in other social justice advocacy contexts. When coupled with a vision of justice that requires inclusion of and respect for difference, such advocacy presents an alternative to the similarity argument. The next Part considers two additional examples of social justice advocacy that used this "anti-discrimination" approach.

\section{III}

\section{THE ANTI-DISCRIMINATION APPROACH}

The history of social justice activism in the United States suggests that use of the similarity argument during the initial stages of reform may be inevitable. Civil rights activists, feminists, gay rights advocates, and the disability rights community have all used the argument that a just society would provide entitlements to the groups they represent (and the individuals within them) because of those groups' similarity to legally protected groups. ${ }^{61}$ However, despite the intuitive appeal of the argument that a just society would treat like entities alike, a model of justice that requires equal treatment only as long as there is similarity between pre-existing and would-be rights-holders can have strong exclusionary effects. This is true especially if a would-be rights-holder has to be similar to pre-existing rights-holders both as to relevant characteristics of the pre-existing rights-holders for purposes of entry and as to how the preexisting rights-holders act in the settings the would-be rights-holder seeks to enter. For example, laws that prohibit race-based discrimination in the sale of real property provide only formal equality of access and use, and not real justice

actually connected to the bone and grows out from the bone. For information about the procedure and its effects on animals, see The Paw Project, http://www.pawproject.com/html (last visited Feb. 20, 2007).

58. I am aware of The Paw Project's advocacy strategy because, when drafting the legislation with Orly Degani and Vicki Steiner, I met and corresponded frequently with Dr. Jennifer Conrad and Dr. Jim Jensvold of The Paw Project. Additionally, I attended a hearing regarding the same proposed legislation before the Malibu City Council.

59. West Hollywood, CAL. CODE $§ 9.49 .020$ (2000).

60. Id. ("No person ... shall perform ... an onychectomy ... on any animal within the city, except when necessary for a therapeutic purpose.") (emphasis added).

61. See supra note 4. 
or equality of access and use, if most people of color are unable to qualify financially or if the uses of real estate must comport with exclusively whitederived standards of nuisance law. Similarly, laws that forbid sex-based discrimination in hiring provide only formal equality of access if women seldom qualify under male-derived standards of qualification or if they can be fired for becoming pregnant. Formal equality based on similarity to white, non-disabled men superficially satisfies the basic requirement of a just society that like entities be treated alike. Nevertheless, it does not readily admit challenges to the relevance of the characteristics used to establish similarity. Nor does it readily allow for newcomers, who qualified for entrance on the basis of similarity, to reshape the environments they have entered. For instance, in a formally equal workplace it would not be unjust to fire an employee who becomes pregnant if justice is based on equal treatment of like entities and the woman is no longer similar to male workers because of a condition to which only women are subject (pregnancy).

Firing the pregnant employee would not be just under all formulations of "equal treatment," however. In addition to formally equal treatment, equal treatment can mean treatment appropriate to allow someone to enter or remain in a group, despite inconvenient dissimilarity, as long as doing so is not unreasonably burdensome to the group. The aim of "appropriately equal" treatment is fairness in outcomes despite dissimilarity. "Appropriately equal" treatment is a model of equality based on accommodation because it provides a basis for challenging the limits established by formally equal treatment. However, both formally equal and appropriately equal treatment rest on the similarity argument because both involve assessments of the newcomer's abilities in relation to an existing structure and its occupants.

Neither formal equality nor appropriate equality requires anticipation and accommodation of dissimilar individuals before such individuals have arrived on the scene. That is the promise of the anti-discrimination approach. The antidiscrimination approach requires employers to create a workplace flexible enough to accommodate the vagaries of (male and female) employees' real lives, including some (male and female) employees' temporary absences due to such circumstances as pregnancy, illness, or the need to provide care to another. Diversity of experience and dissimilar utilization of human environments, such as workplaces, is accepted as so natural and inevitable that, before any individual would have asked for accommodation, a structure of accommodation has been put in place.

Developing inclusive human environments actually alters the definition of what it means to be different. This effect is illustrated by the following questions of Disability Studies Professor Rosemarie Garland-Thomson: "Would people in wheelchairs be considered disabled ... if every building had ramps rather than stairs? Would attention deficit disorder exist as a diagnosis were it not for our demand for a certain kind of attentiveness in the way we 
structure learning and school?", Garland-Thomson is emphasizing the importance of context for determining whether a person is different from others; a person is not for all purposes and at all times "disabled." Significantly, the consequences of anticipatory accommodation can be beneficial for everyone and are not necessarily inconvenient or costly for pre-existing rights-holders. There are benefits of including those who are dissimilar, such as the increased availability of different points of view that assist in meeting organizational challenges. And, if one looks at the concrete effects of an environment that supports diversity, not just the value of inclusion of those formerly excluded, one can find benefits to pre-existing rights-holders. For example, everyone, not just wheelchair users, finds ramps helpful at some times and for some purposes. $^{63}$

The first type of equality (equal treatment as long as the would-be rightsholder is similar both as to initial capability and as to use of the settings) has been the historical first step of inclusion. Formal equality requires that the would-be rights-holder make all the accommodations necessary to function in settings that were designed without them in mind; formal equality demands assimilation. The second type of equality requires consideration of each wouldbe entrant's capability, regardless of apparent dissimilarity to existing members. It reduces the exclusionary effect of formal equality based on the similarity argument because an individual can challenge the fairness of exclusion based on difference. The second type of equality also requires after-inclusion accommodation when newcomers have specific needs that cannot be met by the settings in which they live or work, provided that accommodating those specific needs does not unreasonably conflict with organizational objectives. It does not require assimilation to the degree demanded by formal equality. The third type of equality (anticipatory accommodation of dissimilarity so that exclusion is less likely) is a relatively new formulation of equality characterized by relatively less reliance on the similarity argument, relatively greater anticipation of the diversity among members of the community, and some shifting of the burden of justification from would-be rights-holders (to justify their inclusion) to wouldbe excluders (to justify exclusion).

The examples to follow illustrate advocacy that shifts from exclusive reliance on the first two pathways of equality to tentative emergence of advocacy that envisions a restructured society in which the diversity of all participants is anticipated and accommodated. These examples suggest alternative approaches to the similarity argument that may have application in the context of animal protection. That possibility is explored in Part IV.

62. Rosemarie Garland-Thomson, Disability Needn't Be Liability; Conference Reflects New Perception of an Opportunity, Not a Problem, The AtLAnTA Journal-Const., Mar. 3, 2004, at 15A.

63. This point was explicitly part of the debate regarding the ADA. See PETER BLANCK ET AL., DISABILITY CIVIL RIGHTS LAW AND POLICY 2-31 (2004). 


\section{A. Feminist Pathways to Justice}

In the 1960s and '70s, it was important to women's advocates to emphasize similarities between women and men so that women could gain more equitable access to the workforce and the workplace. ${ }^{64}$ Activists presented women as equal to men in worthiness and in their ability to do the same jobs. Unfortunately, women's "ability to do the same job" was understood as women's doing the same job in the same way and under the same circumstances as men; in other words, assimilation into the workplace as it currently existed was required. ${ }^{65}$ The argument that women are just like men in all relevant ways created downstream problems when women became pregnant, wanted to continue working, and found that their employment contracts and workplace policies or rules made it impossible for them to do so ${ }^{66}$ Women are not just like men, and the difficulties experienced by pregnant employees brought that reality sharply into focus. ${ }^{67}$

At that point, there appeared an ideological fork in the road. One path led down the same similarity-based argument, which would minimize pregnancy as a transient and inconsequential difference between men and women. An endpoint of this path was the Pregnancy Discrimination Act, ${ }^{68}$ enacted in 1978, which required employers to provide to pregnant women the same kinds of accommodations, if any, provided to men who have temporary health conditions or impediments to full workforce participation. ${ }^{69}$ The law predated the Americans with Disabilities Act of $1990,{ }^{70}$ and employers were not required by the Pregnancy Discrimination Act to accommodate any employees' (male or female) disabilities (temporary or permanent). ${ }^{71}$ The Act required only workplace parity between male and female employees similarly situated regarding conditions that prevented their optimal participation in the workforce..$^{72}$ An employer still had the power to decide what would be acceptable employee performance by reference only to the employer's production goals and the employer's beliefs about the abilities of optimally

64. See Lise Vogel, Mothers on the Job: MAternity POLICY IN THE U.S. WorkPlace 13233 (1993) (describing the "assimilation" approach used by women to gain access to societal institutions).

65. Regarding assimilation in the context of the women's movement, see id. at 132-34 (describing the assimilation approach); Littleton, supra note 4, at 1292 (describing the symmetrical approach to sexual equality).

66. See Lucinda M. Finley, Transcending Equality Theory: A Way Out of the Maternity and the Workplace Debate, 86 COLUM. L. REV. 1118, 1123-26 (1986) (describing problems facing pregnant women in a male-centered workplace).

67. See id. at 1139-40, 1141-42, 1143 (outlining unique problems created by pregnancy in the workplace); VOGEL, supra note 64, at 96-97, 136 (discussing the treatment of pregnancy as a disability).

68. Publ. L. No. 95-555, 92 Stat. 2076 (codified at 42 U.S.C. $§ 2000 \mathrm{e}(\mathrm{k})(2000)$ ).

69. 42 U.S.C. $\$ 2000 \mathrm{e}(\mathrm{k})$.

70. Pub. L. No. 101-336, 104 Stat. 327 (1990) (codified at 42 U.S.C. $\$ \$ 12101-12213$ ).

71. See Vogel, supra note 64, at 95 (stating that the Act never even used the word "disability").

72. 42 U.S.C. $§ 2000 \mathrm{e}(\mathrm{k})$; Finley, supra note 66, at 1141, 1145-46; VOGEL, supra note 64, at 100, $134-35$. 
functioning employees. ${ }^{73}$ Accordingly, the Pregnancy Discrimination Act required minimal adaptation on the part of employers, and it furthered an ideology of equal treatment that involved placing women "in the same boat" as had already been created by the employer for male employees. ${ }^{74}$

It is not surprising that emphasis on similarity to male workers and minimizing pregnancy by way of labeling it a temporary disability was the legal path selected. The argument of women's similarity to men for all important workplace purposes was, after all, the path used to gain entrance to the workplace initially. ${ }^{75}$ However, it troubled some activists to participate in identifying a normal life-cycle event such as pregnancy as a "disability." ${ }^{, 76}$ Some activists recognized that doing so left in place as "normal" workplaces that failed to accommodate all-not just female-employees' greater or lesser capacities during the course of their employment. In other words, it was predictable that identifying pregnancy as a disability and arguing that disabilities require accommodation would prevent or delay restructuring the workplace so that people of differing capacities could work productively throughout their years of employment. The moving target of analysis was the worker with greater or lesser degrees of (dis)ability; the stationary framework of analysis was the workplace as ideally envisioned by the employer. With the spotlight on workers' (in)capacities, it was easy for the discussion to revolve around what pregnancy entails in light of what the workplace demands. With the spotlight on workers' (in)capacities, it was not necessary to talk about the design of work and work organizations. ${ }^{77}$

Equally important to the purposes of this analysis, the Pregnancy Discrimination Act required a discussion of the biology of disability. ${ }^{78}$ How is pregnancy "disabling," and how does this "disability" match up with other kinds of disability? Who gets "disabled" by pregnancy, and how typical of pregnant women is such disability? Just as activists for animals currently find themselves arguing that differences between animals and humans are insignificant for the purpose of attaining legal protection, women's activists found themselves arguing that the differences between men and women were insignificant-

73. See Finley, supra note 66, at 1125, 1126-27 (describing the problems facing women in the workforce and the lack of accommodation to women's lives).

74. Id. at 1141, 1145-46; VOGEL, supra note 64, at 100, 134-35.

75. VoGEL, supra note 64, at 133-34; Finley, supra note 66, at 1142.

76. VOGEL, supra note 64, at 94; see generally Finley, supra note 66 (discussing the way men have equated pregnancy to disability and how that mindset has caused problems for women).

77. Finley, supra note 66, at 1120, 1126-27, 1142-43, 1154-58.

78. See Littleton, supra note 4, at 1291-94 (discussing different approaches to sexual equality); see

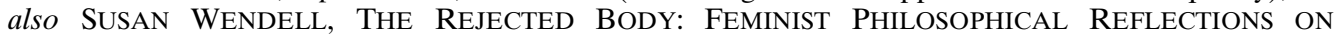
DisABILITY 117 (1996); Melissa Cole, The Mitigation Expectation and the Sutton Court's Closeting of Disabilities, 43 How. L.J. 499, 504-07 (2000) (discussing reliance on medical models of disability preceding and during consideration of the ADA, which postdated the PDA of 1978); Mary Crossley, The Disability Kaleidoscope, 74 NOTRE DAME L. REV. 621, 649-50 (1999) (describing the pernicious effect of reliance on a medical model that defines disability as a personal trait of the person who is disabled and therefore inferior to those who do not have that trait). 
regardless of whether they actually suspected that there might be real, significant differences. ${ }^{79}$

While the tried and true ideological path was taken as to securing workplace accommodation for pregnancy, there was, at least, ideological awareness of another path - a path that would involve restructuring the workplace so that people of varying capacities at any given time in their careers could work in an environment that fully anticipated such variations. Questioning the model of equality based on similarity gained momentum in the next phase of advocacy, which concerned maternity or family leave. Should an employer have to accommodate an employee-male or female-who would not have had the need for accommodation had they not taken on the responsibilities of parenting? Should women have to choose between family and work; or, should the workplace be conceptualized and designed in ways that anticipate employees' having various family-care responsibilities over the course of their careers?

During the late 1980s, feminist activists debated ideology and pragmatic strategy in the context of securing for employees family and medical leaves of absence that would not jeopardize an employee's ability to return to the same position without loss of seniority or pay. ${ }^{80}$ Although the Family and Medical Leave Act of $1993^{81}$ (FMLA) fell short of many activists' goals, at the least it furthered a positive concept of the ability of an employee-whether male or female-to help family members, of any age, and furthered redefinition of employers' expectations of employees. ${ }^{82}$ If those ideas were fully developed and

79. See, e.g., Littleton, supra note 4, at 1291-94 (describing the symmetry approach to sexual equality that women were caused to make).

80. VOGEL, supra note 64, at 106-10; Littleton, supra note 4, at 1291-98; Christine A. Littleton, Does It Still Make Sense to Talk About "Women"?, 1 UCLA WOMEN's L.J. 15, 26-31 (1991); Joan Williams, Do Women Need Special Treatment? Do Feminists Need Equality?, 9 J. CONTEMP. LEGAL ISSUES 279, 281-84 (1998).

81. 29 U.S.C. $\$ \S 2601-2654$ (2000).

82. The stated purpose of the Family and Medical Leave Act was to "balance the demands of the workplace with the needs of families, to promote the stability and economic security of families, and to promote national interests in preserving family integrity[,]" and to "entitle employees to take reasonable leave for medical reasons, for the birth or adoption of a child, and for the care of a child, spouse, or parent who has a serious health condition." Id. § 2601(b)(1)-(2). These purposes were to be accomplished "in a manner that accommodates the legitimate interests of employers[,] ... minimizes the potential for employment discrimination on the basis of sex[, and] promote[s] the goal of equal employment opportunity for women and men" Id. § 2601(b)(3)-(5). When the Supreme Court upheld the FMLA in 2003, Chief Justice Rehnquist reiterated that point and wrote further that

[s]tereotypes about women's domestic roles are reinforced by parallel stereotypes presuming a lack of domestic responsibilities for men. Because employers continued to regard the family as the woman's domain, they often denied men similar accommodations or discouraged them from taking leave. These mutually reinforcing stereotypes created a self-fulfilling cycle of discrimination that forced women to continue to assume the role of primary family caregiver, and fostered employers' stereotypical views about women's commitment to work and their value as employees.... By creating an across-the-board, routine employment benefit for all eligible employees, Congress sought to ensure that family-care leave would no longer be stigmatized as an inordinate drain on the workplace caused by female employees, and that employers could not evade leave obligations simply by hiring men.

Nev. Dep’t of Human Res. v. Hibbs, 538 U.S. 721, 736 (2003). 
implemented, competitive advantage could no longer lie in preventing employees from taking leaves of absence; competitive advantage would have to lie in imaginatively creating a work structure with enough flexibility to allow for compliance with employees' right to take care of family members. The focus on employees' assimilating to workplaces defined by their employers shifted, if imperfectly and incompletely, in the direction of employers' structuring the workplace in anticipation of employees' needs.

Even without complete implementation of the ideology of the FMLA, the social value of family taking care of family gained somewhat in comparison to the social value of employer autonomy. Both values pre-existed enactment of the FMLA, but the relative strength of each changed somewhat as a result of the new discourse about and rationale for seeking enactment of the FMLA. One significant result of this shift would be that one talks less about the effects on employees of parenting or care-taking and more about what work organizations look like when employees are temporarily unavailable. For example, a discourse about whether employees are deserving of taking leaves of absence may well involve discussion about how tiring and emotionally draining care-taking responsibilities are and whether a "typical" employee ought to be able to handle both work and family-care responsibilities. There would be studies of individuals' capacities to cope with lack of sleep and loss of routines to which they are accustomed. By contrast, a discourse premised on the expectation that sometimes an employee will be absent for greater or lesser amounts of time would involve discussion about organizational objectives and strategies and comparative studies of organizations that most competitively address this shift in what employers can expect of employees. From FMLA advocates' point of view, the law may not have changed sufficiently to fully protect employees who, at one time or another, may need to take leaves of absence for medical or family-caretaking purposes. ${ }^{83}$ Nevertheless, enactment of the FMLA shifted the law and legal discourse productively in the direction of requiring employers to anticipate their employees' needs to take leaves of absence. $^{84}$

Nevertheless, there has been sharp criticism of the FMLA, primarily for its failure to require paid leave, which, critics argue, leaves stereotypes in place. For criticism of the FMLA's shortcomings, see generally Lisa Bornstein, Inclusions and Exclusions in Work-Family Policy: The Public Values and Moral Code Embedded in the Family and Medical Leave Act, 10 COLUM. J. GENDER \& L. 77 (2000); and Michael Selmi, Is Something Better Than Nothing?: Critical Reflections on Ten Years of the FMLA, 15 WASH. U. J.L. \& POL'Y 65 (2004).

83. See, e.g., Bornstein, supra note 82; Selmi, supra note 82 (sharply criticizing the lack of mandatory paid leave as the source of continuing disparity in the use of the FMLA provisions and of continuing stereotypes of women as caretakers).

84. There is disagreement about this point. Vogel notes that discourse shifted during the campaign to enact the FMLA, VOGEL, supra note 64, at 108-09, and even FMLA critic Michael Selmi states that family leave has received substantially more attention than it had in the past. Selmi, supra note 82, at 84. However, Selmi criticizes the pursuit of weak legislation (e.g., unpaid family-leave provisions) because it could be predicted from the outset that such legislation would not be used as the advocates proposed and would predictably contribute to continuity of the stereotype of women as caretakers. Although this is the stereotype the legislation purportedly addressed, it would actually perpetuate the 


\section{B. From Formal Equality to Anti-Discrimination in Disability Rights}

The feminist search for equality in the context of valuing differences between and among men and women is ongoing. There is, however, at least evidence of a shift from an ideology of equality that is based on how well the individual mimics the qualities of insiders to an ideology of equality based on envisioning a world in which people with a variety of commitments such as work, health, family, and community can participate. Just as the FMLA ${ }^{85}$ is one indicator of that shift, enactment of the Americans with Disabilities Act of $1990^{86}$ (ADA) suggests that a similar shift has begun concerning participation in American society by individuals with disabilities.

In the disability rights context, the similarity argument arises when disabled individuals claim that they are sufficiently like non-disabled people to warrant inclusion in human environments from which they have been excluded. For instance, when buildings were not constructed with wheelchair accessibility, a wheelchair user could not "reasonably" expect to work or to live in such buildings, and it was "reasonable" for employers and apartment managers to reject applicants who could not enter the buildings in which those applicants would work or live. It was difficult to challenge the reasonability of exclusionary practices based on the design of workplaces and living spaces because those designs seemed inevitable and "natural."

Disability rights advocates began to challenge the reasonability of exclusion by defining "disability" with more precision. Depending on the definition of "disability," disabled people could seem more or less similar to non-disabled people, and it would seem more or less fair to exclude them. Thus, progress for people with disabilities first registered as a more concerted effort to define "disability." "Disability" as some aspect of an individual that makes him or her

stereotype because women, who lose less money during an unpaid leave than men, would be more likely than their husbands to take unpaid leave to care for family members. $I d$. at $75,85-86$.

85. 29 U.S.C. $\$ \S 2601-2654(2000)$.

86. Pub. L. No. 101-336, 104 Stat. 327 (1990) (codified at 42 U.S.C. $\$ \S 12101-12213$ (2000)).

87. BLANCK ET AL., supra note 63. The movement to pass the ADA began with a 1986 report released by the National Council on the Handicapped (later the Nation Council on Disability). TOWARD INDEPENDENCE: AN ASSESSMENT OF FEDERAL LAWS AND PROGRAMS AFFECTING Persons with Disabilities - With Legislative ReCOMMENDATIONS, A RePORT to the PRESIDENT AND TO THE CONGRESS OF THE United STATES (1986). One of the major problems confronted by the Council was developing an adequate approach to defining disability. The two prevailing notions at the time- the "health conditions approach" and the "work disability approach"were both found to be lacking. The health-conditions approach defined disability as any and all conditions that interfered with the "normal functional abilities of an individual." Id. at 2-6. This approach was deemed over-inclusive because it encompassed conditions not typically thought of as disabling, such as skin conditions. $I d$. The work-disability approach focused on conditions that prevent or limit individuals from working, and it was deemed lacking because individuals with disabilities who are working would not be considered disabled, while some people who were not working for reasons that had nothing to do with disability would be considered disabled. Therefore, neither approach worked satisfactorily to define disability. See id. (describing the inadequacies of both approaches). Although an act based on the 1986 Council report was not passed into law at that time, it did become the basis for the ADA of 1990. Id. at 2-7. The ADA defines disability as "(A) a physical or mental impairment that substantially limits one or more of the major life activities of such individual; (B) a record of such an impairment; or (C) being regarded as having such an impairment." 42 U.S.C. § 12102. 
dissimilar to others, the impact of that dissimilarity on the individual who is disabled, and who gets or is disabled for what reasons were all aspects of early considerations of what constitutes a "disability." with disabilities and disabilities per se without reference to how disabilities could be a function of the human environment. The fairness of exclusion and the desirability of including disabled people were seen as related to the nature of the disability and its origin. For example, arguments about whether alcoholism or same-sex orientation were "disabilities" revolved around the medical basis for those states of being and also around whether individuals disabled in these ways deserve accommodation. ${ }^{89}$

88. Richard K. Scotch, Models of Disability and the Americans with Disabilities Act, 21 BERKELEY J. EMP. \& LAB. L. 213, 214 (2000). Scotch claims that the passage of the ADA marked shifts in conceptual understandings of disability and in approaches to federal disability policy. Until the late 1960s, disability was "defined in predominantly medical terms as a chronic functional incapacity whose consequence was functional limitations assumed to result from physical or mental impairment." Id. That model was largely displaced by the socio-political model, in which "disability is viewed not as a physical or mental impairment, but as a social construction shaped by environmental factors, including physical characteristics built into the environment, cultural attitudes and social behaviors, and the institutionalized rules, procedures, and practices of private entities and public organizations." Id. See also Cole, supra note 78, at 504-07 (discussing reliance on medical models of disability preceding and during consideration of the ADA, which postdated the PDA of 1978); Crossley, supra note 78, at 64950 (describing the pernicious effect of reliance on a medical model that defines disability as a personal trait of the person who is disabled and, therefore, inferior to those who do not have that trait); Wendell, supra note 78, at 117; DuAne F. Stroman, The Disability Rights Movement: From DEINSTITUTIONALIZATION TO SELF-DETERMINATION 74 (2003). Stroman notes that the social model of disability was central to the independent living movement of the 1960s and 1970s. Although the medical model focused on trying to habilitate the individual to fit the environment, the social model "emphasizes altering the social and physical environment so that it is less stigmatizing and less restrictive." Id.

89. The medical basis for claiming that homosexuality is a disability may have been its original classification as a "mental disorder" by the American Psychiatric Association (APA) in its Diagnostic and Statistical Manual (DSM). In 1974, long before the ADA was under consideration, homosexuality was no longer listed as a mental disorder, although distress about one's homosexual orientation continued to be listed as such. George Mendelson, Homosexuality and Psychiatric Nosology, 37 AUSTL. \& N.Z. J. PSYCHIATRY 678, 681-82 (2003). Mendelson notes that, despite removal of the designation, the concept of homosexuality as a disorder remained strong enough that a 1998 article published by the APA reported that many countries continue to label homosexuality as a mental disturbance, based on the APA's original classification. $I d$. at 682 . However, the medical basis for disability may also have been the result of socio-cultural conflation of homosexuality with a predisposition toward HIV infection.

The APA also listed "alcoholism" as a mental disorder in its first two editions of the DSM. In the revised third edition (DSM-III-R), the edition in print when the ADA was under consideration, alcohol abuse and dependence were described as including physiological and behavioral symptoms. Alcohol Alert, No. 30 PH 359 (Nat'l Inst. On Alcohol Abuse and Alcoholism, Bethesda, MD), Oct. 1995. Research continues on the subject of a biological basis for alcohol dependence. See, e.g., Jeffrey C. Long et al., Evidence for Genetic Linkage to Alcohol Dependence on Chromosomes 4 and 11 from an Autosome-Wide Scan in an American Indian Population, 81 AM. J. OF MED. Genetics (NEUROPSYCHIATRIC GENETICS) 216 (1998).

Richard Scotch points out that critiques of the ADA have often centered on the moral deservedness of the individuals likely to be covered under the law: "Individuals who have conditions which are associated with engaging in morally questionable behavior or who are perceived as representing a lack of self-control or poor character may be seen as unworthy of public support." Scotch, supra note 88, at 220. Scotch notes that the legislative history of the ADA shows there was considerable "discomfort" with the broad and inclusive definition offered by the bill, which included "people with HIV/AIDS, alcoholism, most psychiatric conditions, and those with a history of substance abuse." Id. Such 
The medical basis for disability and whether justice requires inclusion of disabled people was also evident in discussions about other disabilities such as vision- or movement-impairment, ${ }^{90}$ but eventually advocates began to question the idea that disabilities can be defined solely by comparing people's abilities, irrespective of the environments those people occupy. Consider, for example, two cases of visually impaired individuals. One person can compensate for her visual impairment by wearing glasses, but the other person's impairment is not correctable with glasses. If the first person is not considered disabled but the second person is, then the definition of disability is controlled not by the fact of visual impairment itself but by whether the visually impaired person can make sufficient adjustments to live or work in human environments designed for optimally sighted people. ${ }^{91}$ No adjustment of those environments is necessary if a visually impaired person can assimilate successfully (wear glasses); she is not disabled as to those environments. However, if a visually impaired person cannot assimilate successfully (by wearing glasses, for example), can that person be excluded, or should an employer have to design the workplace so that such a visually impaired person can work without her visual impairment's constituting an insurmountable hurdle to job performance? If an employer is required to anticipate different levels of visual acuity among her employees, her workplace will be an environment in which some people who might be visually impaired in most settings will not be visually impaired in their workplace.

Gradually, recognition has grown that a "disability" is at least partially a problem and result of human environments designed by those who anticipate too narrow a range of occupants. ${ }^{92}$ The ADA incorporates some elements of that recognition and represents some change in the direction of greater accessibility. In general, the ADA requires reasonable accommodation of those who have not been able to participate in various venues of American society but who could do so if reasonable accommodation were provided. The reasonable-accommodation requirements of the ADA do not require anticipatory accommodation of people with different abilities; they require accommodation only if a person can prove that accommodating her disability is a reasonable burden to place on those who would exclude her. Thus, although the mere fact of dissimilarity cannot operate so as to exclude someone, the ADA requires those who seek accommodation to meet a definition of

discomfort also accompanied the passage of the FFHA, as some legislators voiced their aversion to protecting "drug abusers and persons with contagious diseases who pose a threat to others." H.R. Rep. No. $100-711$, at 82 (1988).

90. See Scotch, supra note 88.

91. See Cole, supra note 78 , at 499-500 (pointing out the fallacy in trying to classify every person as either having a disability or not).

92. Scotch claims that the passage of the ADA marked shifts in conceptual understandings of disability and approaches to federal disability policy from the predominant "medical model" to a sociopolitical model in which disability is a construction of the relationship between individuals and their environments. Scotch, supra note 88, at 214. See also STROMAN, supra note 88, at 74 (describing the independent-living movement as a time when emphasis was shifted from rehabilitating the person to rehabilitating the person's environment). 
"disability" without reference to the particular environment they seek to enter and to bear the burden of showing that their disabilities can be reasonably accommodated. Because of those burdens, the reasonable-accommodation provisions of the ADA as originally enacted do not extend as far as some disability rights advocates might have preferred, and courts have further limited the protective potential of the ADA. ${ }^{93}$

Nevertheless, the reasonable-accommodation provisions of the ADA constitute an ideological breakthrough; those provisions embed the idea that people who seek to enter environments for which they are not naturally wellsuited should no longer bear the entire burden of assimilation or be excluded. ${ }^{94}$ "Reasonable accommodation" is a progressive concept in that an employer cannot simply turn away a person with disabilities if she can be reasonably accommodated. Some burden is displaced from the person with disabilities (to make herself compatible with the environment she seeks to enter) and is placed on the entity that controls the environment itself. To the extent that some disabilities are likely to exist among the pool of applicants for a particular position, managers of workplaces have an incentive to anticipate a greater range of individuals using the workplace and to design those workplaces accordingly, even before such applicants appear. ${ }^{95}$

Whereas anticipatory accommodation is a possible result of the reasonable accommodations requirements of the ADA, anticipatory accommodation is explicitly required by some provisions in the ADA and the Federal Fair Housing Act of $1968,{ }^{96}$ as amended in $1988 .{ }^{97}$ The ADA requires new commercial construction design to anticipate the probability that commercial buildings will be used by individuals with a range of accessibility needs. ${ }^{98}$ No

93. Linda Krieger notes that, contrary to media and popular culture constructions of the sweeping protection of the ADA, studies conducted in the late 1990s of the Act's Title I (employment) cases have shown that federal courts have been interpreting the ADA in increasingly narrower ways. For example, "[a] study of federal district court decisions conducted by the American Bar Association reported in 1998 that, in a data set including all published ADA Title I cases that had gone to judgment either before or after trial, plaintiffs lost ninety-two percent of the time. In the Fifth Circuit, the figure was a startling ninety-five percent." Linda Hamilton Krieger, Foreword-Backlash Against the ADA: Interdisciplinary Perspectives and Implications for Social Justice Strategies, 21 BERKELEY J. EMP. \& Lab. L. 1, 7 (2000). See also Ruth O'Brien, Bodies in Revolt: GENDER, Disability, AND A WORKPLACE ETHIC OF CARE 3 (2005).

94. O'BRIEN, supra note 93, at 1-4 (describing the ADA as an ideological turning point in the belief that employees should bear all responsibility for fitting into existing workplaces).

95. Krieger contends that the ADA represents a conceptual understanding of disability as a result of the interaction between "impairment and the surrounding structural and attitudinal environment" such that managers of workplaces are charged with anticipating a greater range of individuals using the workplace, and not just with including people who were previously excluded. Krieger, supra note 93, at 14. This approach (referred to by Scotch, supra note 88, as the socio-political model) presumes that environments, not simply individual differences, cause disabilities. Krieger argues that such a theoretical conception of disability triggers "a societal obligation to change the environment" to accommodate varying levels of ability. Id. (emphasis omitted). See also O'BRIEN, supra note 93, at 4, $11-12$.

96. 42 U.S.C. $\$ \S 3601-3619$ (2000).

97. Pub. L. No. 100-430, 102 Stat. 1619 (1988).

98. See 42 U.S.C. $§ 12183$. 
individual has to prove that she is disabled and that she is going to use the building when it is finished; developers must anticipate that there will be differently abled people using the building. Similarly, the FFHA requires new multifamily residential construction ${ }^{99}$ to anticipate the probability that the residential building will be used by individuals with varying abilities and expectations of using the space. ${ }^{100}$ No individual has to prove that she is disabled or how her disability should be accommodated; the definition of "future occupant" of the building has been extended such that builders must anticipate a wider variety of potential human occupants. ${ }^{101}$

As in the case of reasonable accommodation, the new construction requirements only lessen the burden on people with disabilities, they do not remove it. New construction requirements mandate only creating the structural features (for example, walls strong enough to support grab-bars). ${ }^{102}$ When it comes to actually using the building, an individual may need further reasonable accommodation, such as installing grab-bars. ${ }^{103}$ Moreover, there have been various legal battles over the new construction requirements of the ADA and the FFHA. ${ }^{104}$ Nevertheless, there are signs that the ideology of anticipatory accommodation is continuing to develop. For example, the "visitability" campaign to require all new home construction to have at least one no-step entrance and wider doorways is gaining momentum. ${ }^{105}$ The end result is not

99. The amendments apply to "the design and construction of covered multifamily dwellings." 42 U.S.C. $\S 3604$.

100. See id. (prohibiting making residential buildings unavailable because of handicap).

101. For an example of the breadth of consideration of these issues, see Arlene S. Kanter, A Home of One's Own: The Fair Housing Amendments Act of 1988 and Housing Discrimination Against People with Mental Disabilities, 43 AM. U. L. REV. 925 (1994) (describing how the Fair Housing Amendments Act of 1988 has been used to protect people with mental disabilities from housing discrimination).

102. H.R. REP. NO. 101-485 pt. 1, at 116-18 (1990).

103. Id.

104. These legal problems range from grand-scale issues about the ADA's lack of enforcement mechanisms, BLANCK ET AL., supra note 63, at 2-34, to questions about whether a third story of a nightclub qualifies as a "mezzanine" or a "story," and whether renovations to an already existing structure are "alterations" or "new construction." Laird v. Redwood Trust L.L.C., 392 F.3d 661 (4th Cir. 2004) (holding that the third-floor area was small enough to be considered a "mezzanine," and thus not subject to the ADA accessibility requirements of "stories," and that inaccessible renovations were "alterations," and thus did not require accessibility as long as the services provided there were available in other, accessible spaces). The legal problems that accompanied the passage of the FHAA have run the spectrum as well, ranging from litigation aimed at defining the scope of the amendments, Robert L. Schonfeld, "Reasonable Accommodation" Under the Federal Fair Housing Amendments Act, 25 FORDHAM URB. L.J. 413 (1998), to clarifying specific building requirements, Baltimore Neighborhoods, Inc. v. Rommel Builders, Inc., 40 F. Supp. 2d 700, 708 (D. Md. 1999).

105. This approach to new home design foresees and includes users across a spectrum of ability and sizes, and does not conceive of accessibility as a design "problem" only for wheelchair users and people with disabilities. Advocates of the movement assert that design accommodations to achieve visitability, such as no-step entrances, wider doorways, fewer interior doors, and larger bathrooms, would be inexpensive and easily accomplished. Ragged Edge Online, Visitability: Becoming a National Trend?, http://www.raggededgemagazine.com/0103/visitability.html (last visited Oct. 31, 2006). A federal bill requiring that "all newly constructed, federally assisted, single-family houses and town houses to meet minimum standards of visitability for persons with disabilities," is currently being debated in Congress. Inclusive Home Design Act, H.R. 1441, 109th Cong. (2005). 
simply that some people who could not access or use these settings now can; the end result is that a broader range of people through a broader range of their lifetimes can use these buildings. ${ }^{106}$

Similarly, within the design community, the idea of "one-size-fits-all" is yielding to the understanding that one size cannot possibility fit all and that it is more appropriate to anticipate a range of diverse users of a design. ${ }^{107}$ Universal Design, as it is called, involves anticipating many different kinds of "average" users rather than one archetypical "average" user ${ }^{108}$ and reduces the need for people to customize one-size-fits-all designs. Office chair design is an example of a shift from designing with an average user in mind to designing chairs that anticipate different users by allowing adjustments to chair height, tilt, and lumbar support. ${ }^{109}$ More people can find office chairs that suggest to them that they are normal or typical chair users. Most importantly, the prevalence of alternative designs itself carries a message of diversity as normal and normatively acceptable, even if the purpose of redesigning chairs is only to sell more chairs. ${ }^{110}$

In summary, both examples of feminist and disability rights advocacy involve the following elements: decreasing attention paid to arguments about the worthiness of individuals who seek access and protection; increasing focus on anticipatory accommodation such that difference is "naturalized;" and implicit assumption of the value of inclusion. In the process, equality as a function of being similar to those who already have rights or access is gradually replaced with equality as a function of structures that are designed to permit or even expand the range of participatory possibility to those who had not been included, even before and without the demand having been made-anticipatory accommodation. Feminist and disability rights advocates are also increasingly asking that those who seek to discriminate against others bear the burden of justifying that discrimination. Is it possible to use elements of this same path in advocacy for animals?

106. A former opponent of a bill in Georgia that would have increased the new construction requirements imposed on developers acknowledged that he did not fully understand the need for this type of construction foresight until his father suffered a stroke. Ragged Edge Online, supra note 105.

107. See Martha Albertson Fineman, Foreword to Ruth O'BrIEN, BODIES IN REVOLT: GENDER, DisABILITY, AND A WORKPLACE ETHIC OF CARE, at xiii (describing the designing trend that recognizes the "commercial value of accommodating differences across the range of potential customers").

108. Id.

109. For the history and politics of chair design, see GALEN CRANZ, THE CHAIR: RETHINKING Culture, Body, AND DESIGN (1998).

110. See Fineman, supra note 107. 


\section{EXAMPLES OF THE ANTI-DISCRIMINATION APPROACH IN ADVOCACY FOR}

\section{ANIMALS}

Two examples of progress for animals obtained without reliance on the similarity argument are the Endangered Species Act of 1973 (ESA) ${ }^{111}$ and the development of artificial wildlife corridors. The former protects endangered species and their habitats from intentional, human-caused harms. The latter enables wild animals to live more safely in areas that have roads because the artificial corridors provide pathways above or under those roads. For reasons discussed later ${ }^{112}$ neither is a flawless example of the anti-discrimination approach in action. Nevertheless, both contain the following elements: (1) animals are protected without reference to how closely they approximate human beings; (2) necessities of life, such as habitat and species preservation, are protected; (3) animals' interests are anticipated and accommodated despite costs to humans; and (4) burdens of justification are shifted to some extent to those who would harm animals.

\section{A. The Endangered Species Act}

The ESA is a particularly significant example of seeking reform via the antidiscrimination approach because protection under the ESA is explicitly premised on the value of diversity among animals and plants. ${ }^{113}$ The purpose of the ESA is to conserve endangered or threatened species and their habitats. ${ }^{114}$ For that purpose it is not necessary to prove that members of the species think or feel like humans, and endangered species are not ordered hierarchically by reference to how closely their members resemble humans. ${ }^{115}$ Moreover, the

111. 16 U.S.C. $\$ \S 1531-1544(2000)$.

112. See infra text at nn.121-37 \& 141-42.

113. Diversity as a value may, in this case, be tempered by human preferences for some species. Although the ESA requires the Secretary of the Interior to protect all endangered species and to prioritize only according to the degree to which they are endangered, various critics of the enforcement of the Act have found that funding of species recovery programs is heavily skewed toward "charismatic megafauna" (chiefly telegenic mammals and birds popular with the American public) and away from species with which humans are less readily able to identify, such as reptiles, insects, and crustaceans. See, e.g., Jason Scott Johnston, The Tragedy of Centralization: The Political Economics of American Natural Resource Federalism, 74 U. COLO. L. REV. 487, 565 (2003); Andrew Metrick \& Martin L. Weitzman, Patterns of Behavior in Endangered Species Preservation, 72 LAND ECON. 1, 11 (1996); Jon Welner, Natural Communities Conservation Planning: An Ecosystem Approach to Protecting Endangered Species, 47 STAN. L. REV. 319, 335-36 (1995).

114. 16 U.S.C. § 1531(b). See also id. § 1532(6) (defining "endangered species" as "any species which is in danger of extinction throughout all or a significant portion of its range" other than certain excluded insect pests); id. $§ 1532(20)$ (defining "threatened species" as any species likely to become endangered within the foreseeable future). Although the ESA protects "endangered" species and "threatened" species, for purposes of this article, I use only the term "endangered" to refer to both groups.

115. 16 U.S.C. $\S 1533(\mathrm{a})-(\mathrm{c})$ (establishing no hierarchy for the determination and listing of endangered species); id. $\S 1533$ (f)(1)(A) (requiring the Secretary of the Interior to develop recovery plans for threatened or endangered species, giving "priority to those endangered species or threatened species, without regard to taxonomic classification, that are most likely to benefit from such plans"). 
types and number of animal species covered by the ESA are extensive. ${ }^{116}$ Invertebrates, as well as vertebrates, are protected; insects, fish, and many living beings not commonly known are protected under the ESA. ${ }^{117}$ Protection of look-alike species or sub-species that are not endangered expands the protective reach of the ESA; look-alike species can be listed because of the possibility of mistakenly "taking" an endangered species when targeting a nonendangered species. ${ }^{118}$

In addition to protecting a wide array of animal and plant species, the ESA also protects endangered species' habitats. By protecting endangered species' habitats, the ESA protects the means by which endangered and non-endangered animals living in the same habitats survive. In that way, ecosystems that would have been disrupted by the loss of potentially key members of the system will not be disrupted. While look-alike species are protected in relation to prohibited "takings" of endangered species, even non-endangered species that are dissimilar from endangered species are protected to some extent if they share the same habitat with endangered or look-alike species. ${ }^{119}$ Thus, the ESA protects many more animals than might be expected from a law whose title is restricted to "endangered" species.

Habitat is protected by prohibiting direct harm to endangered animals but also by requiring permits for development. Developers must receive specific authorization to develop land on which endangered species are living, and permits will not be issued if development would further threaten an endangered

116. According to the National Endangered Species Act Reform Coalition, as of June 25, 2001, there were 1,244 species listed as endangered or threatened under the ESA, with another 213 species proposed for listing. NESARC Web Page, http://www.nesarc.org/species.htm (last visited Oct. 31, 2006). For the United States government's complete, daily-updated lists of animal or plant species officially listed as threatened or endangered, see U.S. Fish \& Wildlife Service, Species Information: Threatened and Endangered Animals and Plants, http://www.fws.gov/endangered/wildlife.html\#Species (last visited Oct. 31, 2006). Regarding the ongoing debate over improper political influences, economic considerations, favoritism toward certain species, and other similar external factors in the process by which the Fish \& Wildlife Service lists or delists species, see, for example, J.R. DeShazo \& Jody Freeman, The Congressional Competition to Control Delegated Power, 81 TEX. L. REV. 1443, 1466-67 (2003); Oliver A. Houck, The Endangered Species Act and its Implementation by the U.S. Departments of Interior and Commerce, 64 U. COLO. L. REV. 278 (1993); Metrick \& Weitzman, supra note 113, at 13-14; Benjamin M. Simon et al., Allocating Scarce Resources for Endangered Species Recovery, 14 J. POL'Y ANALYSIS \& MGMT. 415, 430-32 (1995).

117. 16 U.S.C. $§ 1532(8)$ ("The term 'fish or wildlife' means any member of the animal kingdom, including without limitation any mammal, fish, bird (including any migratory, nonmigratory, or endangered bird for which protection is also afforded by treaty or other international agreement), amphibian, reptile, mollusk, crustacean, arthropod or other invertebrate, and includes any part, product, egg, or offspring thereof, or the dead body or parts thereof."); id. § 1532(14) ("The term 'plant' means any member of the plant kingdom, including seeds, roots and other parts thereof.").

118. 16 U.S.C. $\S 1533(\mathrm{e})(\mathrm{A})-(\mathrm{C})$. If there is the possibility of confusion between two species, one endangered and one not, the one not endangered may be protected for the purpose of protecting the endangered species. Stephen M. Fernandez, Captive-Bred Exceptions: An Unconventional Approach to Conservation Under the Federal Endangered Species Act, 15 U. FLA. J. L. \& PUB. POL'Y 155, 163-64 (2003).

119. Although a non-endangered animal could be hunted in the eco-system he shares with endangered species, preservation of habitat provides a type of protection the non-endangered animal would not have had at all, if he had not lived an eco-system with endangered species. 
species. ${ }^{120}$ According to environmental protection scholar Ken Geiser, this provision embodies the two primary characteristics of the "precautionary principle," a concept developed in environmental law that requires those who might cause environmental harm to (1) refrain from potentially harmful acts, even if scientific research has not yet proved the exact nature of the potential harm or the degree of risk of harm, and (2) bear the burden of proving that potentially harmful acts are sufficiently safe before proceeding. ${ }^{121}$ The ESA does

120. 16 U.S.C. $\S 1539(a)(1)-(2)$ (authorizing federal authorities to grant permits to allow incidental taking of endangered species as a result of otherwise-lawful activities). Regarding the U.S. Fish and Wildlife Service's habitat conservation plan program requiring land developers to develop plans to conserve endangered species habitat prior to obtaining development permits, see generally J.B. Ruhl, How to Kill Endangered Species, Legally: The Nuts and Bolts of Endangered Species Act "HCP" Permits for Real Estate Development, 5 ENVTL. LAW. 345 (1999).

121. Ken Geiser, Establishing a General Duty of Precaution in Environmental Protection Policies in the United States, in Protecting Public Health \& THE EnVIRONMENT: ImPlementing the PreCAutionary PRINCIPLE, xxi, xxiii (Carolyn Raffensperger \& Joel A. Tickner eds., 1999). Both aspects - the idea of pre-emptive protection before harm occurs and requiring those who would create risk to prove that their acts would not be harmful-are attractive. In fact, more social justice movement advocates are exploring the utility of the precautionary principle. For instance, legal scholar Anita Bernstein has described developments in sexual-harassment law through the lens of the precautionary principle. Anita Bernstein, Precaution and Respect, in Protecting Public HeAlth \& THE ENVIRONMENT: IMPlementing THE PRECAUTIONARY PRINCIPLE, supra, at 148. Steven Wise has examined its use in animal advocacy, albeit after animals' similarity to humans has been established. Wise, supra note 7, at 35-38.

To the extent that the precautionary principle raises doubt about resting decisions on scientific evaluations as currently conducted, the precautionary principle could ameliorate one of the pragmatic problems with the similarity argument (i.e., that it promotes scientific research to determine with certainty whether animals are similar to humans). As it was initially developed in environmental law, the precautionary principle requires restraint even without scientific proof of potential harm, as long as it is reasonable to suspect that there is risk. The precautionary principle thereby decreases reliance on scientific assessments for fear of over-reliance on scientific method and on scientists charged with making evaluations. Liz Fisher claims that such fear is partially the result of general misunderstanding and ignorance about science. Liz Fisher, Review of The Precautionary Principle in the Twentieth Century: Late Lessons from Early Warnings, 15 J. ENVTL. L. 104, 104-05 (2003). However, such fear may also indicate misgivings about having placed so much authority in a scientific technocracy. Bernard D. Goldstein \& Russellyn S. Carruth, Implications of the Precautionary Principle for Environmental Regulation in the United States: Examples from the Control of Hazardous Pollutants in the 1990 Clean Air Act Amendments, 66 LAW \& CONTEMP. PROBS. 247, 248-49 (Autumn 2003). Jordan and O'Riordan agree that distrust of the scientific method and concerns about the introduction of risky technologies, processes, and products have strengthened the appeal of the precautionary principle. Andrew Jordan \& Timothy O'Riordan, The Precautionary Principle in Contemporary Environmental Policy and Politics, in Protecting Public Health \& THE ENVIRONMENT: IMPLEMENTing the PRECAUTIONARY PRINCIPLE, supra, at 15, 17.

Despite its apparent value, the concept is controversial. Cass Sunstein, among others, strongly criticizes the precautionary principle for its potential to paralyze decisionmaking with uncertainty about regulatory inaction or action because the threshold for risk and action is not defined. CASS R. Sunstein, Laws of FeAR: Beyond the Precautionary Principle 13-34 (2005). See also Frank B. Cross, Paradoxical Perils of the Precautionary Principle, 53 WASH. \& LEE L. REV. 851 (1996) (discussing how regulations based on the precautionary principle can perversely cause a net detriment to public health or the environment by restricting potentially risky products or practices, preventing the benefits of their use, and thus producing worse harms than the risks or harms avoided). Sunstein regards the precautionary principle as a "crude way of protecting ... goals, which should be pursued directly." Cass Sunstein, Beyond the Precautionary Principle, 151 U. Pa. L. Rev. 1003, 1005 (2003). The claim of uncertainty goes to the definitional problems associated with the precautionary principle. See, e.g., Sumudu Atapattu, Evolution and Status of the Precautionary Principle in International Law by Arie Trouwborst, 96 AM. J. INT'L L. 1016, 1016 (2002) (book review). Yet Jordan and O'Riordan claim that 
include those concepts as to various permit requirements, but, since animals are already listed as endangered before they receive protection under the ESA, the precautionary principle would offer more protection if it could be used in ways that prevent species from becoming endangered in the first place.

Despite impressive protections provided by the ESA, the ESA does not provide everything that an advocate for animals might seek via the similarity argument. Notably, the ESA does not provide protection of individual animals or an individual animal's way of life. ${ }^{122}$ Members of endangered species can spend their entire lives in zoo cages constructed of bars and concrete floors. ${ }^{123}$ Certainly, the Act does not protect an animal from research. ${ }^{124}$ For instance, great apes are endangered, but the ESA has not removed the possibility of using them for research experiments that benefit humans exclusively. ${ }^{125}$ Indeed, their rarity, as defined by the ESA, provides legal protection only from extinction; their similarity to humans may actually have made them preferred subjects of experimentation. ${ }^{126}$

As for protection at the species level, ESA protection is designed only to prevent species extinction, and species' extinction is considered a problem for humans rather than primarily a problem for the animals covered by the Act. ${ }^{127}$

the primary value and potency of the precautionary principle may well lie in the amorphous state of its definition. Jordan \& O'Riordan, supra, at 15-16. That amorphous quality might actually be the source of its benefit to social justice activists.

122. The ESA does provide protections of habitat, but the ESA does not address individual animal's concerns, such as each individual's utilization of a habitat or an individual's risk of death, for example. 16 U.S.C. $\S 1533(\mathrm{a})(3)(\mathrm{A})$ (Secretary of Interior shall designate critical habitat for any species designated as threatened or endangered); $i d$. $\S 1534(\mathrm{a})-(\mathrm{b})$ (federal officials shall use land-acquisition authority or available funds to acquire land for habitat).

123. 16 U.S.C. § 1539(a)(1) (allowing the Secretary of the Interior to conditionally permit otherwise forbidden "takings" of animals "for scientific purposes or to enhance the propagation or survival of the affected species"); id. § 1532(19) ("The term 'take' means to harass, harm, pursue, hunt, shoot, wound, kill, trap, capture, or collect, or to attempt to engage in any such conduct.").

124. See 16 U.S.C. $§ 1539$ (a)(1) (permitting research on animals under certain circumstances).

125. See id.

126. Testing Times, ECONOMIST, June 8, 2006, at 81, 82 ("Great apes are man's closest relatives, having parted company from the human family tree only a few million years ago. Hence it can be (and is) argued that they are indispensable for certain sorts of research.").

Richard Ryder, a leader in the animal protection movement, has argued that "[scientists] cannot have it both ways; either men and animals are entirely different, in which case much of their work is invalid, or else men and the other animals are rather the same, in which case animals logically deserve similar treatment and consideration." Richard Ryder, Speciesism, in ANIMAL EXPERIMENTATION: THE MORAL ISSUES, supra note 12, at 36-37.

127. See, e.g., 16 U.S.C. § 1531(a)(3) ("The Congress finds and declares that ... these species of fish, wildlife, and plants are of esthetic, ecological, educational, historical, recreational, and scientific value to the Nation and its people ...."); id. § 1531(a)(5) (stating that congressional purpose includes "better safeguarding, for the benefit of all citizens, the Nation's heritage in fish, wildlife, and plants."); H.R. Rep. No. 93-412, at 5 (1973) (noting that genetic variations among plants and animals constitute potentially valuable resources for addressing human problems such as cancer); Sen. Alan Cranston's remarks on the introduction of the Nature Protection Act, 117 CONG. REC. 560 (1971) ("The various species and subspecies are a part of the diversity of nature which we should preserve for the education and enjoyment of future generations of man. Animals are fun to see and to experience. Our kids ought to have the opportunity that our parents had to know and love wildlife and nature. In addition, taxonomists and other specialists within the biological sciences will obviously benefit if we preserve as many life forms as possible."). 
Animals should be valuable enough to preserve and protect before species endangerment occurs. Moreover, to the extent that advocacy rests explicitly on human interests and only implicitly on animal interests, such advocacy may reinforce social norms of animal protection less directly and fully than advocacy that rests explicitly on animal interests. ${ }^{128}$ According to this argument, in order to reinforce social norms of animal protection, one must be explicit that animals are the intended beneficiaries of the advocacy. Arguably, the ESA underscores the normative expectation that decisions about animals are made with regard to human interests in animals rather than underscoring normative expectations of animal protection. ${ }^{129}$

It seems intuitively correct that advocacy based explicitly on animal protection promotes social norms of animal protection more directly than advocacy that only implies those norms. The similarity argument explicitly calls for protection of animals, and advocacy based on the similarity argument promotes social norms of animal protection directly and explicitly. However, it is very hard to succeed by way of the similarity argument, and "success" via the similarity argument carries significant hazards for animals. Moreover, whereas explicit advocacy may most strongly reinforce norms of animal protection, it is not true that only actions undertaken explicitly to protect animals can reinforce such norms. It is possible that much turns on how developed the norms of animal protection are prior to a specific advocacy campaign. If such norms are very weak or non-existent, then explicit advocacy may be of greater importance in initially building those norms. If the norms are sufficiently strong, then enough people will perceive the actual fact of increased animal protection as related to those norms, whether or not those norms were explicitly invoked during the advocacy process. In such cases, even non-explicit advocacy will reinforce norms of animal protection. The ESA, by protecting animals in fact, implies that animals are valuable, which in turn reinforces the norm of protecting animals, particularly as to that segment of the population that perceives the ESA primarily through the lens of protecting animals for their own sake.

\section{B. Artificial Wildlife Corridors}

Another example of advocacy that does not depend on the similarity argument is the construction of pathways by which wildlife may safely cross under or over busy roadways that divide their ranges. Perhaps the most recent

128. See, e.g., Donovan \& Adams, supra note 47, at 4 ("[M]any efforts on behalf of animals will qualitatively improve humans' living conditions as well. ... But such an argument reduces an analysis of interspecies oppression to a human-centered perspective. Yes, in terms of reducing environmental degradation, challenging the mal-distribution of food because of the squandering of food resources in the production of 'meat,' and preventing human diseases associated with eating animals ... it is true that it is in humans' interest to be attentive to and to challenge animal exploitation. But these responses concede to an insidious anthropocentrism while trying to dislodge it.").

129. Gary Francione has argued that the ESA is premised only on preserving human values and not on protecting animals based on their own inherent value. FRANCIONE, supra note 28, at 183. 
example is a proposal in Washington to construct an extensive system of artificial wildlife pathways to preserve wildlife corridors and wildlife utilization of habitat, which have been lost or compromised when roadways cut through wildlife habitat. ${ }^{130}$ This ambitious plan presently includes up to fourteen crossings, some of which are large, artificial bridges as wide as 1200 feet, planted with dense, native vegetation. ${ }^{131}$ There will be tunnel crossings for animals less likely to use overpasses and fencing to direct wildlife into the crossing areas. ${ }^{132}$ Planners considered the desirability of corridors in order to avoid genetic problems resulting from inbreeding within isolated groups of animals, how animals will use the corridors, and the need to be patient as animals learn to use (or grow up using) the corridors. ${ }^{133}$

The Washington plan is notable for its size, but it is not unique in concept. ${ }^{134}$ Several smaller systems of artificial corridors already exist. Such systems in the Florida everglades allow safe passage for alligators, Florida panthers, armadillos, and foxes. ${ }^{135}$ Artificial corridors outside Barstow, California, benefit the desert tortoise, ${ }^{136}$ and others in southern Montana benefit animals small enough to traverse culverts under roadways. ${ }^{137}$

130. According to the L.A. Times, although other states have artificial wildlife corridors in place, the Washington plan is comparable in scale to the animal-crossing system in Canada's Banff National Park, which is "made of two grass-covered 150-foot wide overpasses and 22 smaller underpasses that cross the Trans-Canada Highway." Tomas Alex Tizon, Designing a Passing Lane for Wildlife, L.A. TIMES, July 24, 2005, at A1, A26.

131. Id. at A26.

132. $I d$.

133. $I d$.

134. See, e.g., Blaine Harden, Saving Lives of Moose and Men, WASH. Post, May 3, 2004, at A01 (discussing the problem of vehicle collisions with moose in Maine); Kirk Nielsen, Slaughter Alley, MiAMI NEW TIMES, June 14, 2001 (on file with author), available at http://www.miaminewt imes.com/issues/2001-06-14/metro.html (describing the horror that can result from seeing animals hit by motor vehicles); Warren Richey, How Did the Toad Hop Across the Road?, CHRISTIAN SCI. MONITOR, Feb. 25, 1999, at 14 (discussing the corridor in the Florida everglades).

135. Tizon, supra note 130 , at A1.

136. Harden, supra note 134, at A01; Tizon, supra note 130, at A26.

137. A scientist at the University of Montana and a for-profit business partnered to develop and market the Critter Crawl, which is a metal shelf suspended inside culverts that already run under roads. The floor of the shelf is designed for easy, safe footing, and the device includes an internal enclosed passageway for smaller animals that might not otherwise use an enclosed walkway also used by their predators. Animals' ability to use the device safely was important to the project, and the device protects animals so small that they would not have posed a substantial threat to humans' safety in the event of motorist collisions with animals. However, it is not clear that the Critter Crawl was developed primarily due to a concern about animals' safety. The idea for the invention reportedly arose out of public concern about the expansion of a highway in southern Montana, but the highway expansion was taking place in wetlands, and public concern might have arisen in the context of concerns about compliance with wetlands-impact-mitigation requirements rather than a concern about animals' safety. Off Beat: Professor Protects Critters, GREAT FAlls TrIB., Apr. 10, 2005, at 1M (citing the need to protect endangered and threatened species while widening the road); "Critter Crawl" Invention Earns Patent, U. Mont. News \& Events Calendar, http://news.umt.edu/index.asp?sec $=1 \&$ too $=100 \&$ dat $=3 / 17 /$ $2005 \&$ sta $=2 \&$ wee $=3 \&$ eve $=8 \&$ npa $=678$ (last visited Oct. 31, 2006) (citing public concern over animals' ability to cross a four-lane highway as a reason for a corridor).

Significant for the utility of this perspective for animals' advocates, however, is the report that the for-profit entity will market the invention more widely than its current use in wetlands. There are plans 
To the extent that animals' advocates were involved in securing these pathways, advocates do not seem to have relied on the argument that animals suffer horribly as a result of motorist collisions with animals or that the animal beneficiaries of the corridors deserve them because animals are like peopleother than perhaps that animals, like people, sometimes need to cross a road to get to the other side. ${ }^{138}$ However, the impact on animals of road construction that fails to provide passageways for animals, such as loss of habitat, increased exposure to predators, loss of genetic diversity with resultant weakening of animals' physical constitutions, and death due to collision with motorists, do seem to have been considered. The end result of including these animal issues was redefinition of "road construction." In praising the Washington plan as a progressive and enlightened approach to road construction, Charlie Raines, a leader of a coalition in support of the plan, stated, "It's not the old approach of 'We just do concrete."' ${ }^{139}$ Road construction had shifted in the direction of planners' anticipating and accommodating the interests of animals as well as the interests of humans.

Research on the efficacy of wildlife corridors to protect wildlife suggests that the wildlife corridors do improve animals' safety, diversity, and access to habitat. ${ }^{140}$ Researchers tend to focus on particular species in particular locations ${ }^{141}$ but, after reviewing all available published studies on the question of artificial habitat connectivity (wildlife corridors), two researchers concluded that the benefits are so great that "those who would destroy the last remnants of natural connectivity [which is generally more extensive than that constructed by humans] should bear the burden of proving that corridor destruction will not harm target populations." ${ }^{142}$

Despite the tantalizing prospect of redefining road construction to include concern for animal fatalities and a shift in the burden of justification for destruction of habitat connectivity, the example of artificial wildlife corridors shares some similarities with the Endangered Species Act that make both of them less than ideal examples of animal advocacy successes accomplished without reliance on the similarity argument. For one thing, no (ab)user of animals would be likely to wage a campaign against either project, thereby

to market the Critter Crawl in areas of high population growth and in areas where American Indian tribal land is involved because "Native Americans have a high regard for 'critter' safety ...." Id.

138. See, e.g., Tizon, supra note 130, at A26 (citing the possibility of in-breeding or injuries to humans as reasons for the corridor); Richey, supra note 134, at 14 (citing the need to protect animal and human lives as a reason for the corridor); Harden, supra note 134, at A01 (citing injuries to humans as a reason for corridors).

139. Tizon, supra note 130, at A26.

140. See, e.g., Paul Beier \& Reed F. Noss, Do Habitat Corridors Provide Connectivity?, 12 Conservation Biology 1241, 1249 (1998); Richard H. Yahner \& Carolyn G. Mahan, Depredation of Artificial Ground Nests in a Managed, Forested Landscape, 10 CONSERVATION BIOLOGY 285, 286-87 (1996); Do Wildlife Corridors Work? Studying Butterflies and Fragments of Open Landscape, SCI. DAILY, June 11, 1999, http://www.sciencedaily.com/releases/1999/06/990611075146.htm.

141. See, e.g., Beier \& Noss, supra note 140, at 1250-52 (stating that birds are often the focus of corridor studies).

142. Id. at 1250 . 
increasing the probability that animals' advocates would end up defending their position on the ground that animals are similar enough to humans that they deserve consideration and protection. ${ }^{143}$ As noted earlier, the ESA has not had much impact on research or other consumptive uses of animals, and the largest consumer of wildlife (hunters) would be unlikely to protest measures that reduce road-kill and keep more of their target animals alive. Accordingly, there were limited occasions to force on animals' advocates an argument about the deservedness of animals to receive greater protection than they currently receive.

More fundamentally, some might criticize the ESA and wildlife corridor construction on grounds that both were last resort efforts to save animals who should not have been endangered or experience habitat connectivity problems in the first place and that neither significantly advances an ideology of protection specific to or focused on animals themselves. The ESA protects animals for the benefit of humans who do not want animal species to become extinct, and wildlife corridors are justified as reducing motorists' collisions with animals. As noted earlier with regard to the ESA, using a means of helping animals that does not require discussion of protecting animals for animals' sake has been criticized as further entrenching beliefs about animals' lack of importance. ${ }^{144}$ Animals may be beneficiaries, but if they are not consciously intended beneficiaries, such developments of which they are unintended beneficiaries may not be helpful in setting the stage for future advances. Stated differently, the argument is that, while animal protection may result from actions undertaken for reasons other than protecting animals, social norms of animal protection will not have been reinforced if such norms are not the explicit basis of reform.

On the other hand, approaching a project as though norms of animal protection are already fully developed might be an effective way to build what are, in fact, relatively undeveloped norms, as long as some normative support already exists. ${ }^{145}$ For instance, building a wildlife corridor may not imply to everyone that animals' lives matter if the explicit reason for the project was to reduce motorist/animal collisions. Nevertheless, if it is understood by enough people that the corridor was built to protect animals because animals are

143. This is not to say that neither escaped opposition. The ESA was (and continues to be) opposed by defenders of private property rights, claiming unfair and burdensome restrictions on development and land use. Wildlife corridor projects are subject to opposition, also, on grounds of costs of construction. See, e.g., Tizon, supra note 130, at A26 (quoting Washington State Senate Minority Leader Bill Finkbeiner questioning the cost-benefit ratio of the project).

144. See supra note 127 and accompanying text.

145. Approaching a problem as though it is already a socio-cultural norm to protect animals has analogs in that form of psychotherapy known as cognitive behavioral therapy in which patients challenge underlying unproductive or irrational beliefs by behaving as though they believed differently, that is, in more productive or rational ways, thereby habituating themselves to that different way of living and changing their beliefs. See JUdiTH S. BECK, COGNITIVE THERAPY: BASICS AND BEYOND 164 (1995); ARTHUR FREEMAN ET AL., CliniCAL APPLICATIONS OF COGNITIVE THERAPY 90 (2d ed. 2004). 
worthy of protection, then the norm of animal protection may be reinforced despite the fact that the project was not expressly initiated primarily for the purpose of protecting animals. ${ }^{146}$

It is difficult to know definitively whether there is sufficient normative support for animal protection such that implicit advocacy would serve to reinforce those norms. Arguably there is. Even those who take opposing sides on the appropriate advocacy strategy agree that most Americans accept the idea that animals can suffer and that it is wrong to inflict pain on a being we know will suffer as a result. ${ }^{147}$ It is tempting to use as evidence the fact that all states have enacted anti-cruelty statutes, some as early as the $1880 \mathrm{~s} .{ }^{148}$ However, the existence of anti-cruelty statutes does not by itself resolve the question because the actual language of anti-cruelty statutes suggests that those statutes may reflect only the value judgment that it is wrong to engage in individual acts of malicious cruelty to animals. Scholars have noted that the anti-cruelty statutes are unhelpful in most cases of institutionalized animal (ab)use, which constitutes the vast majority of animal (ab)use in this society. ${ }^{149}$ They point to legislative historical materials that suggest that the statutes were not enacted primarily for the benefit of animals ${ }^{150}$ and note that anti-cruelty statutes often exempt acts of tormenting and killing animals in such contexts as animal research and flesh-food production..$^{151}$ Thus, there is some question as to what norms of animal protection the statutes reflect.

146. It is possible to engage in "as-if" advocacy while invoking norms of animal protection, of course. One could remind those involved of the need to protect animals for their own sakes. In this wildlife corridor example, however, it is not clear that there were such explicit statements about protecting animals for the sake of the animals themselves. Designing the corridor so that animals would more effectively use it could be related to the goal of increasing roadway safety for motorists who risk fewer collisions if animals are effectively using the corridor. Similarly, habitat connectivity for purposes of maintaining animals' genetic diversity could relate more to humans' interest in maintaining wildlife for their own purposes rather than to a concern for protecting animals for their own sake. News reports do not provide clear evidence of the extent of explicit rationales for the wildlife corridor.

147. See, e.g., Richard A. Posner, Animal Rights: Legal, Philosophical, and Pragmatic Perspectives, in ANIMAL RIGHTS, supra note 7, at 69 ("The soft-utilitarian position on animal rights is a moral intuition of many Americans. We realize that animals feel pain, and we think that to inflict pain without a reason is bad."); Gary L. Francione, Animals-Property or Persons?, in ANIMAL RIGHTS, supra note 7, at 108-09 ("There is a profound disparity between what we say we believe about animals, and how we actually treat them. On the one hand, we claim to take animals seriously.... On the other hand, our actual treatment of animals stands in stark contrast to our proclamations about our regard for their moral status.").

148. Animal Welfare Institute, Animals and Their Legal Rights: A Survey of AMERICAN LAWS FROM 1641-1990, 4 (4th ed. 1990); SONIA S. WAISMAN ET AL., ANIMAL LAW: CASES AND MATERIALS 399 (2d ed. 2002); David Favre \& Vivien Tsang, The Development of AntiCruelty Laws During the 1800's, DETROIT C. L. REV. 1 (1993), available at http://www.animallaw.info/articles/arusfavrehistcruelty1993.htm.

149. Favre \& Tsang, supra note 148; FRANCIONE, supra note 12, at 134-60.

150. Favre \& Tsang, supra note 148; FRANCIONE, supra note 12, at 135-39.

151. FRANCIONE, supra note 12, at 139-56; Favre \& Tsang, supra note 148; David J. Wolfson \& Mariann Sullivan, Foxes in the Hen House: Animals, Agribusiness, and the Law: A Modern American Fable, in ANIMAL RIGHTS, supra note 7, at 205 (considering problems of applying anti-cruelty statutes to flesh-food production). 
This may be a problem of analysis of the literal language of anti-cruelty statutes versus what people think the anti-cruelty statutes provide; the normative expectation created by the mere existence of anti-cruelty statutes may be quite different than the reality of protection afforded by those statutes. ${ }^{152}$ The existence of anti-cruelty statutes attests to the public's belief that animals should be protected from harm and that they are protected from harm, regardless of the very real difficulties involved in actually using those statutes to protect animals. Thus, there may well be enough normative support for animal protection that such norms can be reinforced through advocacy that implies normative support for animal protection, without the necessity of engaging in explicit debates about why we should accommodate the interests of animals.

In summary, the examples of the ESA and artificial wildlife corridors are representative of an anti-discrimination approach in that they support values of diversity and anticipatory accommodation of animals' interests. These examples also illustrate several advantages over arguing for the increased protection of animals because of their similarities to humans. Neither starts from an ideological position of human superiority that inevitably leads to arguments about whether animals are deserving of protection because of their approximation to humans. For the purpose of providing protection, neither creates a hierarchy of worthiness based on how closely certain animals approximate humans. Finally, both are grounded in immediate problem-solving that in actual effect spares the lives of animals. In bypassing the justification stage and proceeding directly to the problem of saving animals' lives, the end result of the ESA and artificial wildlife corridors is pragmatically useful and reinforces norms of animal protection.

\section{$\mathrm{V}$ \\ CONCLUSION}

The similarity argument that justice requires like treatment of like entities underlies most advocacy for animals. It represents the actual beliefs of many advocates for animals, and it has longstanding currency in social justice activism. The similarity argument influences advocates' choice of projects, such as The Great Ape Project, and it emerges in attempts to pass animal-respecting legislation, such as the ban on foie gras production in which it was disputed that geese suffer since their esophagi are apparently different from those of humans. It is also present in advocacy based on litigation, such as claiming loss of

152. Legal scholars David Wolfson and Mariann Sullivan contend that even though anti-cruelty statutes are not actually useful in addressing cruelty that occurs in the production of flesh-food products, "there is still a basic belief on the part of the American public, and legal scholarship, that while all may not be right in the way we treat farmed animals, there are laws, albeit imperfect ones, that govern the industry." Wolfson \& Sullivan, supra note 151 (considering problems of applying anticruelty statutes to flesh-food production). 
companionship when a companion animal has been wrongfully injured or killed. ${ }^{153}$

Unfortunately, the similarity argument has several shortcomings. Advocacy based on similarity proceeds with great difficulty when differences are obvious. Opponents readily reject proffered bases of similarity and find new bases for their claims of dissimilarity. Opponents have incentives to prove dissimilarity because findings of similarity sufficient to invoke the similarity argument call into question moral entitlements to exploit animals. When opponents seek to prove dissimilarity or advocates seek to prove similarity to the rigorous degree required by their opponents, both use controlled scientific research to prove their claims. This conflicts with goals of reducing or eliminating research on animals, and it is particularly troubling if the point of comparison under experimental research review is animals' capacity to suffer. For purposes of scientific curiosity or human benefit, animals are already subjected to painful research procedures. The similarity argument provides an additional reason for subjecting animals to such procedures-to prove that animals suffer like humans. It is no small ethical problem for animals' advocates to create incentives for such research or to use such research in their advocacy. ${ }^{154}$ It is all the more troubling to stimulate research on animals if, as our knowledge of

153. See, e.g., Rebecca J. Huss, Valuing Man's and Woman's Best Friend: The Moral and Legal Status of Companion Animals, 86 MARQ. L. REV. 47 (2002) (placing the issue of market value calculations in the context of general moral and legal valuation of companion animals); Steven M. Wise, Recovery of Common Law Damages for Emotional Distress, Loss of Society, and Loss of Companionship for the Wrongful Death of a Companion Animal, 4 ANIMAL L. 34 (1998) (discussing different theories for recovery of damages that reflect the actual value of companion animals and various theories of recovery).

The similarity argument operates in this context as a claim that companion animals are sufficiently like humans in their relationships with humans that justice requires that harms to animals be valued the way harms to humans are valued. Another application of the similarity argument would be the claim that companion animals are sufficiently like humans that justice requires that they be compensated for actionable harms to their companion humans.

154. This ethical problem is not unique to activism for animals. It is an ethical problem as to experimentation on humans as well. The shame of the Tuskegee experiments on African American men, the testing of polio vaccines on children with disabilities, and Nazi experiments on death camp victims are examples of situations in which the question arises of using the research results of unethical experiments. Does one stop such research by the demand that it stop, while using the results for other purposes? Or, does one remove the incentive to conduct such research by refusing to use results, for any purpose, if the underlying research is unethical? See, e.g., JEFFREY KLUGER, SPLENDID SOLUTION: JONAS SALK AND THE CONQUEST OF POLIO 167-80, 184-94, 215-19 (2004) (describing the early testing of Salk's polio vaccine, first at the Polk State School for people with mental disabilities and at the Watson Home for those disabled by polio, and later at the Industrial Home for Crippled Children, before Salk approached the Sewickley Academy, a prep school, for a trial); COUNCIL ON ETHICAL \& JUDICIAL AFFAIRS, INFORMATION FROM UNETHICAL EXPERIMENTS 3, 5 (AMA 1998), available at http://www.ama-assn.org/ama1/pub/upload/mm/369/ceja_5a98.pdf (Recommendation 5 says, "Based on both scientific and moral grounds, data obtained from cruel and inhumane experiments, such as, data collected from the Nazi experiments and data collected from the Tuskegee Study, should virtually never be published or cited."); Peter Mostow, "Like Building on Top of Auschwitz": On the Symbolic Meaning of Using Data from the Nazi Experiments, and on Non-Use as a Form of Memorial, 10 J.L. \& RELIGION 403, 403-23 (1993) (arguing that the symbolic value of the non-use of Nazi data outweighs any benefits to using the data and generalizing this principle to the non-use of data from other unethical studies, specifically the Tuskegee Syphilis Study). 
humans and animals increases, old questions about similarity are simply replaced with new questions about similarity, and if, therefore, fundamental questions about similarity are never answered with finality. After all, it is unrealistic to expect humans to readily relinquish the oppositional categories of "human" and "animal" when humans have defined themselves as "not animal" for so long. ${ }^{155}$

The similarity argument has other serious flaws. It requires representing animals not by reference to their complexity, but by reference to whether they have one or a few characteristics considered essential to being human. Thus, the ideological basis for justice that like entities be treated alike is disrespectful to animals because it requires proof that they are, in essence, humans. The wondrous diversity of human and animal life is both muted and mooted by the similarity argument, and adopting the standard of "Man is the Measure of All Things" 156 leads inexorably to the development of a hierarchy of worth and access to resources. The similarity argument cannot have a transformative effect on society because neither the status quo's acceptance of "man as the measure" nor the hierarchical ordering of access to resources is challenged by the similarity argument.

Having experienced analogous problems associated with the similarity argument, advocates in other social justice movements have embarked on advocacy premised on a different model of justice. Whatever else may be required of a just society, a just society should operate from a basis of respect for diversity and inclusion of differently situated entities to the greatest extent possible. In fact, a just society would seek ever greater levels of inclusion and accommodation of difference, and, in so doing, just practices that require inclusion and respect would increasingly "naturalize" difference. This is a core aspect of the anti-discrimination approach.

Part III traced the emergence of the anti-discrimination approach through examples from feminist and disability rights advocacy: the Family and Medical Leave Act of $1993^{157}$ and the Americans with Disabilities Act of $1990^{158}$, respectively. Both laws require "anticipatory accommodation" of those whose circumstances would previously have been the basis for exclusion. Such anticipatory accommodation transforms the very nature of what it means to be

155. Historian Morris Berman traces the historical path of humans in separating themselves from nature and from animals, who are viewed increasingly as "others" and as "resources." MORRIS Berman, Coming to Our SEnses: Body and Spirit in the Hidden History of the West (1998). See generally Cary Wolfe, Animal Rites: American Culture, The Discourse of SPECIES, AND POSTHUMANIST THEORY (2003) (discussing humans' treatment of animals as "others").

156. Two meanings are associated with this statement attributed to Protagoras. One is that man is the standard against which all else is measured. The other is that human judgments are idiosyncratically related to the particular individual making the judgment. The second interpretation criticizes the extent to which people can be objective. Protagoras, Internet Encyclopedia of Philosophy, http://www.iep.utm.edu/p/protagor.htm\#SH3b (last visited Feb. 21, 2007). Both meanings are relevant in criticizing the similarity argument.

157. 29 U.S.C. $\$ \S 2601-2654$ (2000).

158. 42 U.S.C. $\S \S 12101-12213$ (2000). 
dissimilar. If a work organization is structured in anticipation of employees taking leaves of absence, then an employee who takes a leave is not dissimilar from others, and he does not need "special accommodation." If a building is built in anticipation of wheelchair users, then a wheelchair user is not dissimilar from others as to access in that building, and he does not need "special accommodation" for purposes of access. New differences will emerge if old differences fade into the background, but decisions based on the values of inclusion and diversity would lead to incremental naturalization of those differences as well. Thus, laws based on anticipatory accommodation not only support values of inclusion and diversity as to current definitions of "difference"; by changing the nature of "difference," they provide ideological support for further applications of those values.

Both the FMLA and the ADA also place burdens of justification on those who were previously entitled to exclude or discriminate on the basis of dissimilarity. Previously, employers could require employees to choose between continued employment or taking care of medical problems or family caretaking responsibilities, and developers could build buildings without regard to differently situated occupants. The laws now presume inclusion and accommodation unless, under particular circumstances, it is unreasonable to expect compliance. Like naturalization of difference, shifting the burden of justification to those who would resist practices designed to naturalize difference is a core feature of the anti-discrimination approach.

The examples of the ESA and development of artificial wildlife corridors described in Part IV reveal that animal advocacy is not totally lacking in efforts to employ aspects of an anti-discrimination approach. Neither advance was premised on the argument that animals are similar to humans, and, in fact, diversity is affirmatively supported. Both reinforce aspects of what an animalrespecting society would look like without becoming preoccupied by an effort to prove that animals are similar enough to humans so as to justify protection. An animal-respecting society would protect animals from extinction, preserve animals' habitats, and provide means for animals to cross roads. Both developments also contain aspects of shifting the burden of justification from those who would protect animals to those who would harm animals. Developers must justify development that could harm endangered species, and, in light of documented protection of animals afforded by wildlife corridors, those who would interrupt the connectivity of wild animals' ranges will increasingly bear the burden of justifying their failure to construct wildlife corridors.

Although both examples deal with wildlife, the anti-discrimination approach can be applied in other animal contexts as well. For instance, the West Hollywood ban on declawing was premised on the belief that an animalrespecting society would not subject cats to a procedure that involves amputating the last bone in each toe as well as severing several integral tendons, nerves, and muscles for the sake of protecting furniture. Moreover, the law requires that the procedure be justified as medically necessary for the cat 
before one or more of a cat's claws can be removed. Factory-farmed animal advocacy can be approached this way, too. Opening or facilitating the opening of a vegan restaurant is a form of advocacy that is premised on what an animalrespecting society would look like. As more people discover that vegan food can taste good, they will have less psychological need to justify consumption of flesh-food, and it will be easier for them to acknowledge that flesh-food consumption causes terrible suffering to animals, destroys the environment, and results in human health problems. It will seem to increasing numbers of people that eating animals is cruel, crude, and selfish. Ultimately, it will be meat-eaters rather than vegans who are called upon to justify their food choices.

The examples of the ESA, artificial corridor development, the West Hollywood declaw ban, and advocacy to increase access and receptivity to vegan food illustrate an inductive use of the anti-discrimination approach. Through specific, limited projects premised on what an animal-respecting society would look like, activists can work toward establishing a society about which it can eventually be said that animals are respected. How far that idea of respect would extend is difficult to predict, since we are only just beginning to engage in advocacy based on an anti-discrimination approach. Each project is but a building block in support of the idea that animals matter. By contrast, the similarity argument most often involves a form of deductive activism in which a broad first principle (animals are similar enough to humans as to relevant capacities and characteristics to be treated like humans) is the basis for reform. Since there is considerable dispute about the starting principle, there are significant delays in actually getting to applications of the similarity argument. Much could be accomplished for some animals if the similarity argument were accepted, but precisely because of the breadth of consequences that flow from the similarity argument, it will most likely be rejected.

The anti-discrimination approach is also distinguishable from the similarity argument as to who bears the burden of justification. The similarity argument requires advocates to bear the burden of justifying inclusion of animals' interests. Since the similarity argument requires proof of similarity to humans, that burden is all the greater because of the tremendous actual diversity of animals. Thus, the diversity of animals is a liability under the similarity argument. By contrast, diversity is not a liability under the anti-discrimination approach. Indeed, it sets the anti-discrimination approach in motion. The antidiscrimination approach presumes inclusion and requires justification for exclusion or discrimination. That burden may be relatively easy to overcome initially. However, over time, as values of inclusion and diversity are reinforced and developed, it should become more difficult to justify acting in opposition to those values.

The anti-discrimination approach will take time to develop, and the similarity argument will not disappear any time soon. The similarity argument invokes a familiar concept of justice, and, on a popular level, it creates some sympathy for some animals. The similarity argument also arises in response to 
opponents' use of dissimilarity arguments. That both the FMLA and the ADA continue to bear marks of the similarity argument and the ideology of formal equality reveals that achieving change in underlying paradigms is difficult. ${ }^{159}$ It is logical that the same would occur in the animal context as well. As Marc Bekoff, a field biologist specializing in animal consciousness, has written,

On the basis of (a) common sense, (b) findings in cognitive ethology (the study of animal thinking, consciousness and mind) and (c) the notion of evolutionary continuity, a strong case can be made for admitting great apes into the community of equals. Initially, I was incredulous that such an appeal was even necessary. Next, I found it difficult to conceive that this plea could ever be denied, not only to great apes, but to most nonhuman animals. Considering, however, how many nonhumans are used by humans for anthropocentric ends, I came to see that it was my own stance that was unusual and in need of justification. ${ }^{160}$

It is unfortunate when advocates are drawn into debating exploiters on exploiters' terms. Focus should instead be placed on challenging exploiters' justifications for animal (ab)use and also on providing alternative means of accomplishing the goals exploiters claim they can achieve only by way of exploiting animals.

Another reason the similarity argument will continue to affect advocacy is that the similarity argument fits with other socio-cultural predispositions in ways that the anti-discrimination approach does not. To the extent that the antidiscrimination approach requires a shifting of the burden of justification or incorporates those aspects of the precautionary principle that require restraint if there is potential of harm and justification before going forward with potentially harmful activities, the anti-discrimination approach conflicts with values of minimal interference with business and business innovation. ${ }^{161}$ Those values comport well with placing the burden of justification on the shoulders of advocates seeking change, which matches the allocation of burden underlying the similarity argument. ${ }^{162}$

159. See generally H.R. REP. No. 101, supra note 102; Bornstein, supra note 82 (criticizing the shortcomings of the FMLA); Krieger, supra note 93 (criticizing the narrow construction of the ADA); Selmi, supra note 82 (pointing out weaknesses in the FMLA).

160. Bekoff, supra note 27, at 102.

161. According to John Applegate, the precautionary principle does not appear to take root easily in places with a "long tradition of scientific corporatism and elitism" or in places where business is given extensive latitude to innovate (such as the United States). John S. Applegate, The Taming of the Precautionary Principle, 27 WM. \& MARY ENVTL. L. \& POL'Y REV. 13, 14-15, 20. Nevertheless, its influence has been felt in many different contexts. See Bernstein, supra note 121; Geiser, supra note 121.

162. Conversely, changing the burden of justification to those who exploit animals, as part of the anti-discrimination approach, may raise concerns about compromising values associated with business autonomy and governmental non-interference. Lisa Bornstein notes this problem in the context of enacting the FMLA. Bornstein, supra note 82, at 77 ("Historically, governmental action on work and family issues, constrained by values of privacy, autonomy, self-sufficiency, and minimal government interference, has been limited to piecemeal responses to headline grabbing outrages."). Jordan and O'Riordan consider this to be a problem with the precautionary principle, particularly when it comes to reversing the burden of proof. Jordan \& O'Riordan, supra note 121, at 28 ("[T] his raises profound questions over the degree of freedom to take calculated risks, to innovate, and to compensate for possible losses by building in ameliorative measures."). 
The anti-discrimination approach holds promise despite the continuing existence of the similarity argument. Through conscientious application of the anti-discrimination approach, advocates can pursue projects grounded in respect for the diversity of animals and their unique characteristics. Holding to that course will be difficult because it is easy to be caught in the web of similarity and dissimilarity arguments posed by opponents and reinforced by the underlying value of free-market capitalism. Even so, the web need not be of animals' advocates' own making, and it is important to refocus the discourse whenever animals' advocates are called on to justify the changes they seek. By contributing to the development of the anti-discrimination approach, advocates for animals join other social justice advocates in seeking change based on respect for diversity and anticipatory accommodation of all.

In such a socio-cultural environment, it might seem that consumers would have considerable power. However, consumers do not have access to information about production methods and about good alternatives to products produced through cruel methods. In other words, the "market" works fairly well on the side of business, but the "market" does not work well on the side of the consumer as to the issue of (ab)use of animals in the production of consumer goods.

One way for advocates to operate in the context of values of non-interference with business is to choose projects that make use of the market. The previous example of vegan restaurants may be effective because shaping consumers' preferences is considered a legitimate market objective. However, if competing industries that use animals are powerful enough to create disproportionate and debilitating hardships, then advocates' use of the market would be seriously hampered. For instance, if a company is developing methods of product testing that do not use animals but companies that make animal-based testing products can control the process by which those non-animal-based methods are evaluated, it is possible that the product-testing company that does not use animals would not be participating in the market on a level playing field with companies that use animal-based methods of testing products. 